\title{
Enfoque diagnóstico de las leucemias mieloides agudas pediátricas
}

\author{
Diagnostic approach of pediatric acute myeloid leukemias
}

\author{
D. Cristina López-Jiménez $M B^{1}$, \\ Natalia M. Guevara-Arismendy MSC $^{2}$
}

Resumen: las leucemias son la primera causa de muerte por enfermedad en niños en Colombia, incluso representan la mitad de las muertes por cáncer pediátrico en el país. En la actualidad, la Organización Mundial de la Salud, en conjunto con expertos internacionales, ha actualizado los criterios para la clasificación y el diagnóstico de las neoplasias hematolinfoides, de manera que, con base en todas las pruebas diagnósticas disponibles y las manifestaciones clínicas, se logre el diagnóstico, pronóstico y tratamiento adecuado para cada paciente. No obstante, no todas las herramientas diagnósticas están al alcance en nuestro medio, por lo que se requiere una adecuada interpretación y uso racional de las técnicas disponibles para lograr la clasificación y estadificación más acertada de los pacientes. En términos generales, las leucemias agudas incluyen las mieloides y las linfoides agudas, las cuales presentan diferencias importantes en su origen celular y genético, epidemiología, comportamiento clínico, pronóstico y tratamiento. En este módulo se revisa específicamente la clasificación y el diagnóstico de las leucemias mieloides agudas, con énfasis en las de mayor interés para la población pediátrica.

Palabras clave: leucemia, leucemia mieloide, leucemia mieloide aguda, citometría de flujo, médula ósea, citogenética.

\footnotetext{
1 Microbióloga y Bioanalista. Bacterióloga Hospital Universitario de San Vicente Fundación. Medellín, Colombia.

2 Microbióloga y Bioanalista. MSc en Microbiología y Bioanálisis, con énfasis en Hematología. Bacterióloga Laboratorio Clínico Hematológico. Medellín, Colombia. Correspondencia: Carrera 43C \#5-33, Medellín, Colombia. Correo electrónico: natalia4612@gmail.com

Conflicto de intereses: las autoras declaran que no tienen conflicto de intereses Medicina \& Laboratorio 2016; 22: 111-146

Módulo 1 (La clínica y el laboratorio), número 115. Editora Médica Colombiana S.A. 2016 ${ }^{\circ}$

Recibido el 14 de marzo de 2016; aceptado el 26 de abril de 2016
} 
Abstract: Leukemias are the leading cause of death by disease in children in Colombia, even represent half of pediatric cancer deaths in the country. Currently, the World Health Organization, together with international experts, has updated the classification and diagnosis criteria for hematolymphoid neoplasias. These criteria, based on all available diagnostic tests and clinical manifestations, are established for achieve the diagnosis, prognosis and appropriate treatment for each patient. However, not all diagnostic tools are available in our area, so that a proper interpretation and rational use of available techniques are required to achieve the most accurate classification and staging of patients. Overall, acute leukemias include both acute myeloid and lymphoid, which have important differences in their cellular and genetic origin, epidemiology, clinical behavior, prognosis and treatment. This module specifically reviews the classification and diagnosis of acute myeloid leukemias, with emphasis on some of them of greatest interest to the pediatric population.

Key words: leukemia; myeloid leukemia, acute myeloid leukemia, flow cytometry, bone marrow, cytogenetics.

López-Jiménez DC, Guevara-Arismendy NM. Enfoque diagnóstico de las leucemias mieloides agudas pediátricas. Medicina \& Laboratorio 2016; 22: 111-146.

L as leucemias agudas son un grupo de neoplasias hematológicas que representan la primera causa de muerte por enfermedad en los niños (menores de 15 años) en Colombia. De acuerdo con las estadísticas del proyecto GLOBOCAN (2012) de la Agencia Internacional para la Investigación en Cáncer (IARC; del inglés, International Agency for Research on Cancer) las leucemias son la neoplasia maligna diferente a melanoma más frecuente en la población infantil (0-14 años), que afectan a cuatro de cada 100.000 niños colombianos, representando el $41,2 \%$ del total de casos nuevos de cáncer en este grupo etario y tienen la tasa más alta de mortalidad (2,2 por 100.000 niños), hasta el punto de ser responsables del 50,0\% del total de las muertes por cáncer infantil [1].

En términos generales, las leucemias agudas incluyen las mieloides y las linfoides agudas, siendo estas diferentes en su origen celular y genético, su epidemiología, comportamiento clínico, pronóstico y tratamiento. En el contexto internacional, las leucemias mieloides agudas representan entre el $15 \%$ y el $20 \%$ de casos de leucemia aguda pediátrica, afectan tanto a niños como a niñas y son más frecuentes en infantes y en mayores de 10 años [2-7]. En relación con Colombia, en 2014, con base en las notificaciones al Sistema Nacional de Vigilancia en Salud Pública (SIVIGILA) y según el informe final del Instituto Nacional de Salud sobre cáncer en menores de 18 años, de 948 pacientes nuevos notificados el 10,9\% tenían leucemia mieloide aguda [8]; no obstante, se debe tener presente que estas frecuencias están sujetas a la notificación de eventos y que es posible que se vean afectadas por el subregistro. 
Dada la morbimortalidad e impacto socioeconómico que conllevan las leucemias agudas pediátricas [9], en la actualidad se consideran un evento de vigilancia en salud pública en Colombia y desde 2009, con el propósito de promover un diagnóstico temprano y la identificación adecuada de los pacientes pediátricos con leucemia aguda, los casos sospechosos se deben notificar al SIVIGILA. De acuerdo con los lineamientos actuales del Instituto Nacional de Salud y el Instituto Nacional de Cancerología la observación de uno o más blastos en sangre periférica en pacientes menores de 15 años, en conjunto con la presentación de uno o más signos como fiebre, sangrado, linfadenopatía, esplenomegalia, hepatomegalia, dolor óseo, hiperplasia gingival o nódulos subcutáneos, constituye un caso probable de leucemia aguda pediátrica y es de notificación semanal por parte de las instituciones prestadoras de servicios de salud con servicios oncológicos $[10,11]$.

En este sentido, el diagnóstico rápido y acertado de los pacientes se convierte en la piedra angular de este grave problema que afecta a la población infantil en Colombia y el mundo, y es por esto que la presente revisión tiene como objetivo brindar las herramientas básicas para el diagnóstico adecuado de las leucemias mieloides agudas en pediatría, incluyendo las pruebas de diagnóstico básicas y especializadas que están disponibles en el país. En próximos números de Medicina \& Laboratorio se presentará una revisión sobre las leucemias linfoides agudas, su impacto en pediatría y su diagnóstico. Para desarrollar el tema de esta revisión se realizará una descripción de las generalidades y el diagnóstico de las leucemias mieloides agudas de mayor interés en pediatría, al igual que una breve explicación de la clasificación de las leucemias agudas en general propuesta por la Organización Mundial de la Salud (OMS) en 2016.

\section{Clasificación de las leucemias agudas: criterios de la Organización Mundial de la Salud}

Antes de profundizar en las características de las leucemias mieloides agudas es importante tener presente la clasificación actual (2016) de la OMS propuesta para el establecimiento del diagnóstico y el pronóstico de acuerdo con el subtipo de la neoplasia que padezca el paciente.

Durante las últimas décadas ha habido un gran esfuerzo para unificar los criterios diagnósticos de las neoplasias hematolinfoides, ya que ello favorece la estandarización del diagnóstico y, por ende, el tratamiento de los pacientes. En 2008, la OMS publicó una nueva clasificación de tumores hematopoyéticos y de tejidos linfoides, la cual fue construida a partir de la reunión de expertos de diferentes nacionalidades y una rigurosa revisión de la literatura. Esta clasificación tiene como precepto que se definan enfermedades que se puedan 
diferenciar y diagnosticar adecuadamente a partir de la integración de toda la información disponible, entre ellas las manifestaciones clínicas del paciente y los hallazgos del laboratorio (morfología, citometría de flujo, estudios genéticos y moleculares) [12]. En 2016, Arber y colaboradores [13] dieron a conocer la última revisión por parte de la OMS acerca de la clasificación y el diagnóstico de las neoplasias hematolinfoides, en la que aparecen nuevos subtipos provisionales.

En términos generales, la clasificación primaria se basa en el linaje (mieloide, linfoide, o de células dendríticas-histiocíticas) y en la madurez de las células implicadas (precursores o maduras). De esta forma, para las leucemias agudas, también llamadas neoplasias de precursores, la clasificación general se realiza en tres grupos: a) leucemias mieloides agudas y neoplasias relacionadas, b) leucemia/ linfoma linfoblástico y c) leucemias agudas de linaje ambiguo. A su vez, estos grupos se subdividen en varias categorías, como se referencia en la tabla $1[12,13]$, de acuerdo con los hallazgos clínicos y de laboratorio, con especial énfasis en la citometría de flujo, los estudios genéticos y los moleculares.

\section{Tabla 1. Clasificación de las leucemias agudas propuesta por la OMS}

Leucemia mieloide aguda y neoplasia de precursores relacionados:

- Leucemia mieloide aguda con anormalidades genéticas recurrentes

- Leucemia mieloide aguda con cambios relacionados con mielodisplasias

- Neoplasias mieloides relacionadas con terapia

- Leucemias mieloides agudas, no clasificables en otras categorías

- Sarcomas mieloides

- Proliferaciones mieloides relacionadas con síndrome de Down

Neoplasia blástica de células dendríticas plasmocitoides

Neoplasia de precursores linfoides:

- Leucemia/linfoma linfoblástica B, no clasificable en otras categorías

- Leucemia/linfoma linfoblástica B con anormalidades genéticas recurrentes

- Leucemia/linfoma linfoblástica T

- Leucemia/linfoma linfoblástica de células NK (entidad provisional)

Leucemia aguda de linaje ambiguo:

- Leucemia aguda indiferenciada

- Leucemia aguda de fenotipo mixto con t(9;22)(q34.1;q11.2); BCR-ABL1

- Leucemia aguda de fenotipo mixto con t(v;11q23); rearreglos de KMT2A

- Leucemia aguda de fenotipo mixto, B/mieloide, no clasificable en otras categorías

- Leucemia aguda de fenotipo mixto, T/mieloide, no clasificable en otras categorías

Tomado y modificado de "The 2016 revision to the World Health Organization classification of myeloid neoplasms and acute leukemia" por D.A. Arber y colaboradores, 2016, Blood, 127, p. 2392. Copyright ${ }^{\circ} 2016$ por American Society of Hematology [13].

Como se aclaró, en esta revisión sólo se discutirán las leucemias mieloides agudas, con énfasis en las de mayor interés en la población pediátrica, las cuales se revisarán en subtítulos posteriores. 


\section{Leucemia mieloide aguda}

La leucemia mieloide aguda resulta de la expansión clonal de blastos mieloides (granulocíticos, monocíticos, eritroides o megacariocíticos) en sangre periférica, médula ósea y otros tejidos [14]. Dichos blastos se derivan de un progenitor de médula ósea, el cual sufrió una transformación maligna y obtuvo la capacidad de autorrenovarse, disminuir su tasa de destrucción y, de paso, limitó su capacidad de diferenciación y de maduración celular [15].

\section{¿Cuándo sospechar una leucemia mieloide aguda en el paciente pediátrico?}

Para comenzar con la descripción y clasificación de las leucemias mieloides agudas es importante aclarar que las características de su presentación son muy variadas y, en general, reflejan el grado de falla medular y de extensión extramedular, en caso de que esta última esté presente. La duración de los síntomas puede variar desde días a meses; en la mayoría de los casos el inicio es agudo, aunque en una minoría de pacientes puede ser insidioso. Los signos y síntomas comunes de las leucemias pediátricas se relacionan directamente con el grado de citopenias (disminución de recuentos celulares), ya sea anemia, leucopenia o trombocitopenia [11]. En la tabla 2 se presentan las principales manifestaciones clínicas correspondientes a cada tipo de citopenia $[16,17]$.

\begin{tabular}{lll}
\hline $\begin{array}{l}\text { Tabla 2. Principales manifestaciones clínicas de los pacientes con leucemia aguda } \\
\text { según las citopenias }\end{array}$ & Anemia & Trombocitopenia \\
Leucopenia- neutropenia & - Palidez & - Púrpura \\
- Fiebre & - Astenia & - Petequias \\
- Lesiones en mucosa bucal & - Adinamia & - Gingivorragias \\
- Infecciones graves & - Taquicardia & - Melenas \\
- Infecciones por & - Disnea & - Hematuria \\
microorganismos atípicos & - Falla cardiaca congestiva & - Hemorragias internas, \\
& - Irritabilidad & entre ellas intracraneales \\
\hline
\end{tabular}

Si bien los signos y los síntomas pueden variar según el tipo de leucemia, en los niños con sospecha de leucemia mieloide aguda es frecuente la presencia de adinamia, irritabilidad, pérdida de apetito, vómito, pérdida de peso, palidez, fiebre, dolor de cabeza, dolor óseo, dolor abdominal, esplenomegalia, hepatomegalia, adenomegalia, hipertrofia gingival, infecciones, papiledema, parálisis facial o en extremidades, sangrados en mucosas o piel, petequias, equimosis, entre otros. En caso de que haya infiltración a tejidos diferentes a médula ósea (infiltración extramedular) se pueden presentar síntomas adicionales según 
la zona afectada, entre ellos masas retrooculares, mediastinales, en cuerpos vertebrales o subcutáneas, entre otras, o bien, infiltración al sistema nervioso central $[4,16-18]$.

Por otro lado, las masas, conocidas comúnmente como cloromas, son muy características de las leucemias mieloides agudas, en especial cuando son subcutáneas o cuando aparecen en neonatos. En caso que estas masas afecten los cuerpos vertebrales, es común que los niños manifiesten dolor de pierna o de espalda, debilidad y entumecimiento [16].

\section{Sospecha de leucemia mieloide aguda desde el hemograma}

Con respecto al hemograma, una leucemia mieloide aguda se debe sospechar en caso que se observe una o más citopenias de grado variable, ya sea leucopenia, neutropenia, anemia o trombocitopenia. La anemia, presente en la mayoría de los casos, varía en su gravedad y por lo general es normocítica homogénea; la trombocitopenia se presenta aproximadamente entre el $85 \%$ y el $90 \%$ de los niños con leucemia mieloide aguda y el riesgo hemorrágico aumenta según el grado de trombocitopenia $[4,16]$; además, es frecuente que el volumen plaquetario medio y la fracción de plaquetas inmaduras estén normales, lo cual concuerda con la falla medular que hay durante las leucemias agudas y el cáncer hematológico en general [19].

Respecto a los leucocitos, a pesar de que se tiene la creencia generalizada de que las leucemias cursan con leucocitosis, es importante destacar que en fases tempranas de la enfermedad los niños pueden presentar, de forma opuesta, pancitopenias [16], con o sin presencia de blastos; de hecho, al diagnóstico, alrededor del $50 \%$ de los niños con leucemia mieloide aguda tienen un recuento de leucocitos normal o disminuido [4]. En cuanto a la hiperleucocitosis (recuento de leucocitos mayor que $100 \times 10^{3} / \mu \mathrm{L}$ ), su hallazgo se debe informar oportunamente al personal médico, ya que puede causar leucostasis, es decir, acumulación de los leucocitos en la microvasculatura, con posibles afectaciones neurológicas y diestrés respiratorio [20]. La leucostasis por lo general se relaciona con las leucemias mieloides agudas de linaje monocítico, leucemias con mutaciones de KMT2A o de FLT3/ITD [21].

Otro hallazgo frecuente en las leucemias mieloides agudas es la neutropenia, por lo que se debe diferenciar adecuadamente de la neutropenia característica de la infancia [16]; por ello, ante la disminución de los neutrófilos, la presencia de citopenias adicionales o alteraciones en los gráficos de distribución celular se debe revisar minuciosamente el extendido de sangre periférica para corroborar que no hayan blastos en circulación. Específicamente, en los autoanalizadores que ofrecen recuentos de granulocitos intermedios o de células inmaduras se debe revisar el extendido cuando haya un aumento significativo de estos. 
Además, es importante que los bacteriólogos y microbiólogos conozcan los principios de medición de los autoanalizadores que disponen en sus laboratorios y sepan cómo interpretar los histogramas o dispersogramas que ofrecen los equipos. Como ejemplo, se presentan los hemogramas de un autoanalizador Coulter $^{\circledR}$ (Beckman Coulter Inc., California, Estados Unidos) (véase figura 1) y de un autoanalizador Sysmex ${ }^{\circledR}$ (Sysmex Corporation, Japón) (véase figura 2) de pacientes con leucemia mieloide aguda.
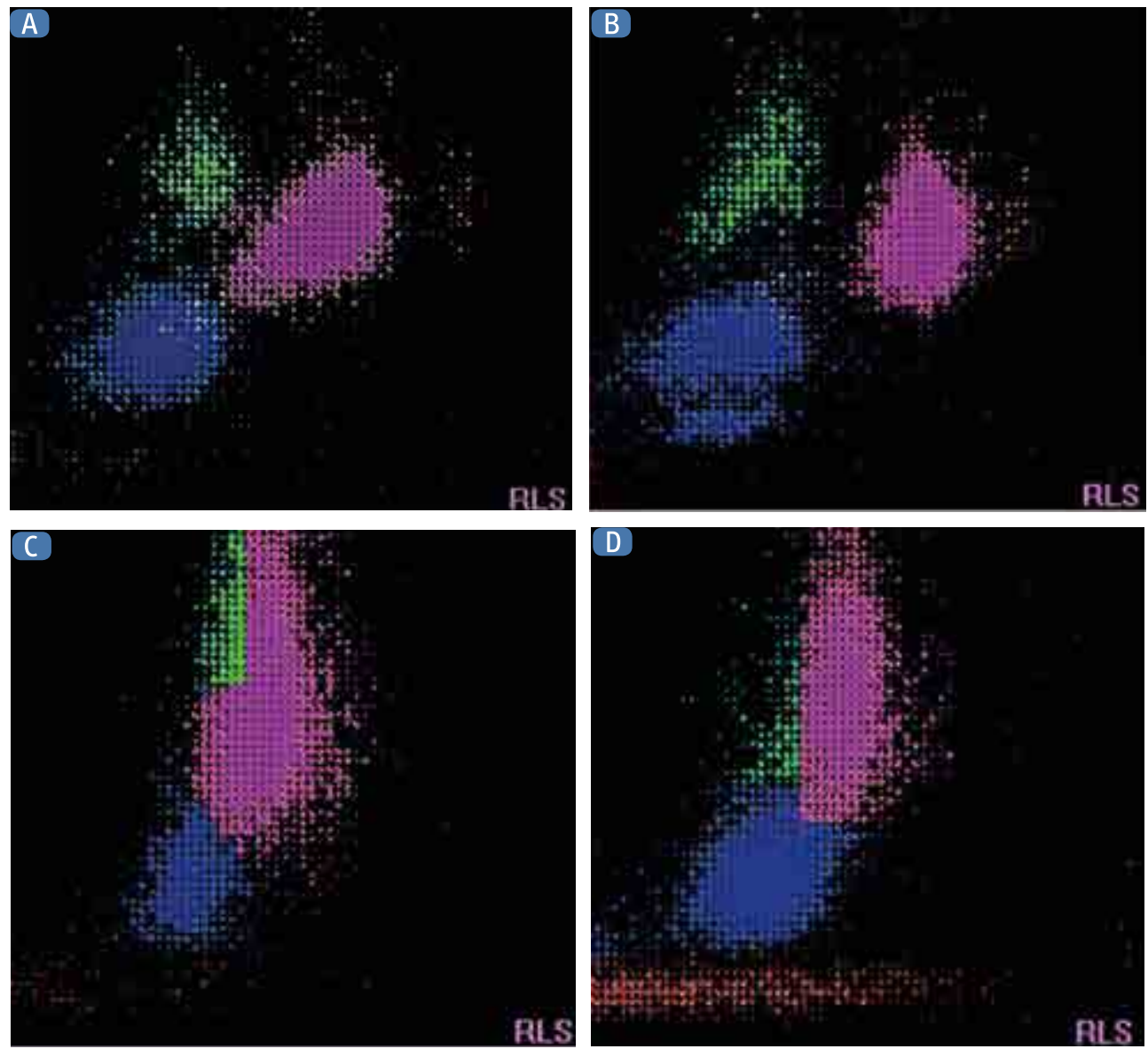

Figura 1. Variaciones en el dispersograma de leucocitos de pacientes con leucemia mieloide aguda en un

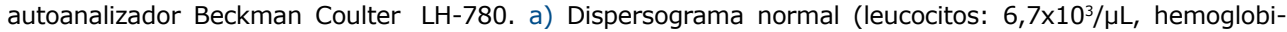
na: $13,8 \mathrm{~g} / \mathrm{dL}$, hematocrito: $40,9 \%$, plaquetas: $\left.289 \times 10^{3} / \mu \mathrm{L}\right)$. b) Hemograma de un paciente con leucemia mieloide aguda y pancitopenia (leucocitos: $3,2 \times 10^{3} / \mu \mathrm{L}$, hemoglobina: $7,8 \mathrm{~g} / \mathrm{dL}$, hematocrito: $23,4 \%$, plaquetas: $25 \times 10^{3} / \mu \mathrm{L}$ ). Obsérvense las alteraciones en la distribución celular en el dispersograma. Entre las alarmas reportadas por el equipo se destacó la posible presencia de células inmaduras/blastos. c) Hemograma de un paciente con leucemia promielocítica aguda PML-RARA. Se encontró leucocitosis y la bicitopenia (leucocitos: $90,1 \times 10^{3} / \mu \mathrm{L}$, hemoglobina: $9,7 \mathrm{~g} / \mathrm{dL}$, hematocrito: $28 \%$, plaquetas: $15 \times 10^{3} / \mu \mathrm{L}$ ). Obsérvense las alteraciones en la distribución celular en el dispersograma, en especial en la región que normalmente corresponde a los neutrófilos y los monocitos. En este caso, el equipo reportó alarma sobre la posible presencia de blastos y de granulocitos intermedios. d) Hemograma de un paciente con leucemia mieloide aguda sin maduración. Se encontró bicitopenia (leucocitos: $6,8 \times 10^{3} / \mu \mathrm{L}$, hemoglobina: $9,5 \mathrm{~g} / \mathrm{dL}$, hematocrito: $26,9 \%$, plaquetas: $57 \times 10^{3} / \mu \mathrm{L}$ ). Obsérvense las alteraciones en la distribución celular en el dispersograma, con unión anormal de varias poblaciones celulares. En este caso, el equipo no alertó sobre la posible presencia de células inmaduras. Cortesía del Laboratorio Clínico Hospital Universitario de San Vicente Fundación. Medellín, Colombia. 

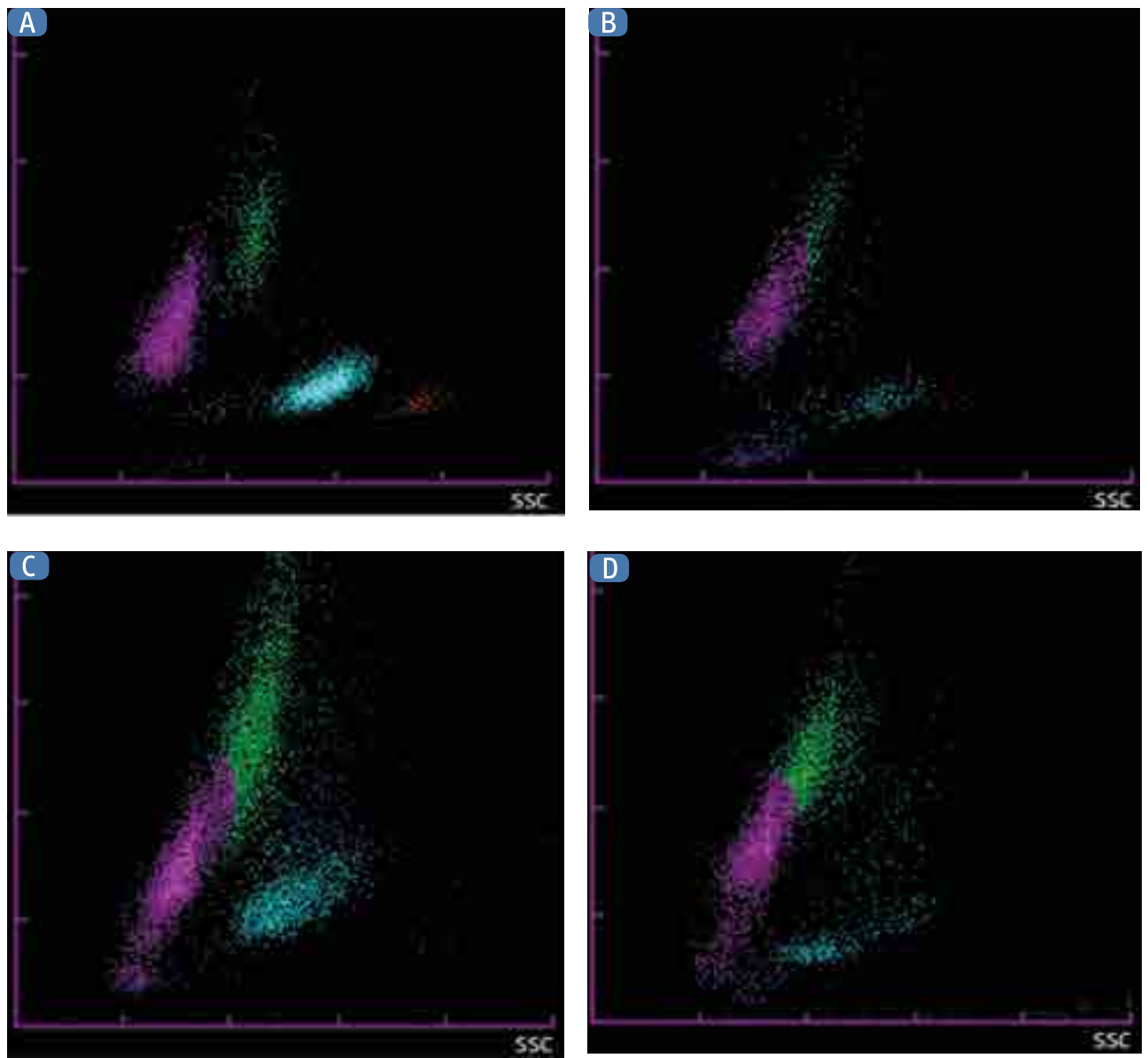

Figura 2. Variaciones en el dispersograma de leucocitos de pacientes con leucemia mieloide aguda en un autoanalizador Sysmex ${ }^{\circledR} \mathrm{XN}-3000$. a) Dispersograma normal (leucocitos: $6,28 \times 10^{3} / \mu \mathrm{L}$, hemoglobina: $14,8 \mathrm{~g} / \mathrm{dL}$, hematocrito: $43,6 \%$, plaquetas: $185 \times 10^{3} / \mu \mathrm{L}$ ). b) Hemograma de un paciente con leucemia mieloide aguda y bicitopenia (leucocitos: $1,9 \times 10^{3} / \mu \mathrm{L}$, hemoglobina: $5,9 \mathrm{~g} / \mathrm{dL}$, hematocrito: $18,1 \%$, plaquetas: $185 \times 10^{3} / \mu \mathrm{L}$ ). Obsérvense las alteraciones en la distribución celular en el dispersograma, principalmente la unión entre la región de los linfocitos y los monocitos. Entre las alarmas reportadas por el equipo se destacó la posible presencia de blastos/linfocitos anormales. c) Hemograma de un paciente con leucemia mieloide aguda y trombocitopenia severa (leucocitos: $8,0 \times 10^{3} / \mu \mathrm{L}$, hemoglobina: $9,7 \mathrm{~g} / \mathrm{dL}$, hematocrito: $32,1 \%$, plaquetas: $6 \times 10^{3} / \mu \mathrm{L}$ ). Obsérvense las alteraciones en la distribución celular en el dispersograma, principalmente la unión entre la región de los linfocitos y los monocitos y la presencia de granulocitos intermedios (región azul encima de neutrófilos). Entre las alarmas reportadas por el equipo se destacó la posible presencia de blastos/linfocitos anormales y la posible presencia de eritroblastos. d) Hemograma de un paciente con leucemia mieloide aguda y bicitopenia (leucocitos: $4,8 \times 10^{3} / \mu \mathrm{L}$, hemoglobina: $7,4 \mathrm{~g} / \mathrm{dL}$, hematocrito: $23,8 \%$, plaquetas: $51 \times 10^{3} / \mu \mathrm{L}$ ). Obsérvense las anormalidades en la distribución celular en el dispersograma. Entre las alarmas reportadas por el equipo se destacó la posible presencia de blastos/linfocitos anormales y la posible presencia de eritroblastos. Cortesía del Laboratorio Clínico Hematológico. Medellín, Colombia.

Por otra parte, los laboratorios clínicos deben tener estandarizados los criterios del hemograma bajo los cuales es imperativo revisar el extendido de sangre periférica; para ello, se puede tomar como base la guía propuesta por la Sociedad Internacional de Laboratorios de Hematología (ISLH; del inglés, Interna- 
tional Society for Laboratory Hematology), la cual define tanto los parámetros cuantitativos como los cualitativos ante los cuales se debe revisar el extendido de sangre periférica $[22,23]$. Algunas de las reglas que sugiere dicha Sociedad para la realización del extendido de sangre periférica y que pueden favorecer la detección de las leucemias mieloides agudas, son:

- Recuento de leucocitos menor que $4 \times 10^{3} / \mu \mathrm{L}$, mayor que $30 \times 10^{3} / \mu \mathrm{L}$ por primera vez o que cambió respecto al recuento previo.

- Recuento de plaquetas menor que $100 \times 10^{3} / \mu \mathrm{L}$ o mayor que $1.000 \times 10^{3} / \mu \mathrm{L}$ por primera vez o que cambió respecto al recuento previo.

- Hemoglobina menor que $7 \mathrm{~g} / \mathrm{dL}$ por primera vez

- Recuento de neutrófilos menor que $1 \times 10^{3} / \mu \mathrm{L}$ o mayor que $20 \times 10^{3} / \mu \mathrm{L}$

- Recuento de linfocitos mayor que $7 \times 10^{3} / \mu \mathrm{L}$ en menores de 12 años y mayor que $5 \times 10^{3} / \mu \mathrm{L}$ en pacientes de 13 años en adelante.

- Recuento de monocitos mayor que $1,5 \times 10^{3} / \mu \mathrm{L}$ en adultos y mayor que $3,0 \times 10^{3} / \mu \mathrm{L}$ en menores de 12 años.

- Recuento de eosinófilos mayor que $2,0 \times 10^{3} / \mu \mathrm{L}$ o de basófilos mayor que $0,5 \times 10^{3} / \mu \mathrm{L}$

- Cualquier valor de eritroblastos

- Alarmas de los autoanalizadores de hematología, en cualquier momento que indiquen:

- Granulocitos inmaduros

- Linfocitos atípicos

- Blastos

- Eritroblastos

Lo anterior, establece la revisión del extendido como prueba refleja y minimiza el riesgo de falsos negativos; no obstante, cada laboratorio debe definir si se ajusta a dicha guía o si adapta algunos valores de acuerdo con la población estudiada. Además, se debe tener presente la sensibilidad de cada autoanalizador para detectar las alteraciones morfológicas de cada población celular.

En resumen, es importante tener claridad que ante una alteración en el hemograma de un niño la sospecha de leucemia aumenta si se aprecian células inmadu- 
ras en el frotis de sangre periférica, si están afectadas dos o más series del hemograma a la vez, si el niño presenta adenopatías, hepatomegalia o esplenomegalia y si no se identifican causas infecciosas que expliquen los hallazgos previos.

\section{Exámenes complementarios en pacientes pediátricos con sospecha de leucemia mieloide aguda}

Con base en las manifestaciones clínicas mencionadas y los hallazgos en el hemograma, entre los exámenes iniciales en un paciente pediátrico con sospecha de leucemia mieloide aguda, y de cualquier leucemia aguda pediátrica en general, se debe incluir el hemograma completo (con recuento de plaquetas y extendido de sangre periférica), niveles de electrolitos, pruebas de función hepática y renal, niveles de ácido fólico, vitamina $B_{12}$, ferritina, pruebas de detección de hepatitis virales y del virus de la inmunodeficiencia humana (VIH) y radiografía de tórax [18]. Además, se sugiere complementar los estudios con pruebas de coagulación, medición de las fracciones del complemento C3 y C4, inmunoglobulinas en suero, títulos de anticuerpos para varicela y citomegalovirus, entre otras pruebas [16].

Posteriormente, el estudio se debe complementar con estudios de aspirado y biopsia de médula ósea, citometría de flujo, moleculares y citogenéticos, de líquido cefalorraquídeo, entre otros [24], como se discutirá para cada tipo de leucemia. En el caso del estudio de líquido cefalorraquídeo, este se debe evitar inicialmente en pacientes con trombocitopenia severa, por lo cual se debe esperar hasta que se realicen transfusiones o se estabilice el recuento plaquetario. Morfológicamente, en el contexto de un niño con diagnóstico de leucemia aguda en general, un estudio de líquido cefalorraquídeo se considera positivo para infiltración cuando se observan más de $5 \times 10^{6}$ leucocitos/L o en el sedimento obtenido por citocentrifugación se observan blastos, entre otros criterios $[16,24,25]$.

\section{Clasificación de las leucemias mieloides agudas}

De acuerdo con los criterios de la OMS (véase tabla 1), en términos generales, para el diagnóstico inicial de las leucemias mieloides agudas se requiere mínimo la presencia del $20 \%$ de blastos mieloides en médula ósea, sangre periférica o ambas, o bien, de las alteraciones citogenéticas $t(8 ; 21)$ (q22; q22); RUNX1-RUNX1T1, inv(16)(p13.1q22) o t(16;16)(p13.1;q22); CBFB-MYH11 o PML-RARA [14], las cuales se discutirán posteriormente. Esta clasificación, que va más allá del porcentaje de blastos, resulta de los avances científicos en el campo oncológico, donde se ha demostrado la importancia de las alteraciones citogenéticas en el diagnóstico, el tratamiento y el pronóstico de los pacientes. 
La leucemia mieloide aguda varía según el linaje o los linajes implicados, el grado de maduración celular, las manifestaciones clínicas y las alteraciones citogenéticas y moleculares implicadas. Con base en lo anterior, la OMS definió seis grandes grupos de leucemias mieloides agudas (con anormalidades genéticas recurrentes, con cambios relacionados con mielodisplasias, relacionadas con terapia, no clasificables en otras categorías, sarcomas mieloides y proliferaciones mieloides relacionadas con síndrome de Down), como se describió en la tabla 1.

Debido a la cantidad de subtipos, en esta revisión sólo se enfatizará en tres grupos de leucemias mieloides agudas: a) leucemia mieloide aguda con anormalidades genéticas recurrentes, b) leucemias mieloides agudas no clasificables en otras categorías y c) proliferaciones mieloides relacionadas con síndrome de Down, que se presentan a continuación.

\section{Leucemia mieloide aguda con anormalidades genéticas recurrentes}

Para el grupo de leucemias mieloides agudas con anormalidades genéticas recurrentes el estudio citogenético y molecular resulta imprescindible para el adecuado diagnóstico de estas neoplasias. Una de las razones por las cuales se deben realizar estos estudios es que en algunos de los subtipos no se requiere un mínimo de blastos, sino que es suficiente con detectar una alteración citogenética o molecular específica para clasificarla como leucemia aguda, es decir, algunos pacientes pueden tener menos del $20 \%$ de blastos y aun así la entidad se clasifica como leucemia aguda. Tal es el caso de la leucemia mieloide aguda con $\mathrm{t}(8 ; 21)(\mathrm{q} 22 ; \mathrm{q} 22)$; RUNX1-RUNX1T1, la leucemia mieloide aguda con inv(16)(p13.1q22) o t(16;16)(p13.1; q22); CBFB-MYH11 y la leucemia promielocítica aguda con PML-RARA. Las leucemias mieloides agudas con anormalidades genéticas recurrentes son las siguientes $[13,26]$ :

- Leucemia mieloide aguda con t(8;21)(q22;q22.1); RUNX1-RUNX1T1

- Leucemia mieloide aguda con inv(16)(p13.1q22) o t(16;16)(p13.1;q22); CBFB-MYH11

- Leucemia promielocítica aguda con PML-RARA

- Leucemia mieloide aguda con $\mathrm{t}(9 ; 11)(\mathrm{p} 21.3 ; \mathrm{q} 23.3) ;$ MLLT3-KMT2A

- Leucemia mieloide aguda con t(6;9)(p23;q34.1); DEK-NUP214

- Leucemia mieloide aguda con $\operatorname{inv}(3)(q 21.3 q 26.2)$ o t(3;3)(q21;q26.2); RPN1-EVI1 
- Leucemia mieloide aguda (megacarioblástica) con $t(1 ; 22)(p 13 ; q 13)$; RBM15-MKL1

- Leucemia mieloide aguda BCR-ABL (entidad provisional)

- Leucemia mieloide aguda con mutaciones de NPM1

- Leucemia mieloide aguda con mutaciones bialélicas de CEBPA

- Leucemia mieloide aguda con mutación RUNX1 (entidad provisional)

En la tabla 3 se mencionan algunas de las alteraciones genéticas que afectan con mayor frecuencia a la población pediátrica, así como sus principales características clínicas y de laboratorio. Algunas de las leucemias citadas en la tabla no hacen parte de las leucemias mieloides agudas con alteraciones genéticas recurrentes. Posteriormente, se enfatizará en la leucemia promielocítica aguda y la leucemia mieloide aguda con $\mathrm{t}(9 ; 11)(\mathrm{p} 22 ; \mathrm{q} 23)$; MLLT3-KMT2A como modelos de la forma en que se deberían diagnosticar las neoplasias de este grupo.

\section{Leucemia promielocítica aguda con PML-RARA}

La leucemia promielocítica aguda es un subtipo único y diferente de leucemia mieloide aguda, con buena respuesta al tratamiento pero con alta mortalidad si no se diagnostica y trata a tiempo. Anteriormente, se conocía como leucemia aguda M3 de la clasificación Francesa-Americana-Británica (FAB). En la clasificación de la OMS de 2008 se denominaba leucemia promielocítica aguda con $\mathrm{t}(15 ; 17)(\mathrm{q} 22 ; \mathrm{q} 12)$; PML-RARA; sin embargo, como algunas veces la translocación es críptica o compleja, pero todas dan como resultado el transcripto fusión PML-RARA, en la actualización de 2016 se aclaró que el nombre más acertado para esta enfermedad es leucemia promielocítica aguda con PML-RARA [13].

Debido a que todas las leucemias promielocíticas agudas presentan una alteración genética estrechamente ligada con el origen y el tratamiento, en la actualidad se considera un subtipo de leucemia mieloide aguda con alteración genética recurrente. En este subtipo de leucemia, las células de casi todos los pacientes tienen una translocación recíproca balanceada entre los cromosomas 15 y 17, que causa la fusión de los genes RARA (receptor a del ácido retinoico) en el cromosoma 17 y el PML en el cromosoma 15. En ocasiones se presentan otro tipo de alteraciones, pero todas incluyen el rearreglo del gen RARA. Teniendo en cuenta su origen molecular, el tratamiento se realiza con ácido transrretinoico y los pacientes presentan excelente respuesta siempre que se inicie rápidamente [42-46]. 
Tabla 3. Leucemias mieloides agudas con alteraciones genéticas más frecuentes en la población pediátrica

\begin{tabular}{|c|c|c|c|}
\hline $\begin{array}{l}\text { Leucemia mieloide } \\
\text { aguda con alteración } \\
\text { genética recurrente }\end{array}$ & Epidemiología & $\begin{array}{l}\text { Valor } \\
\text { pronóstico }\end{array}$ & Hallazgos de laboratorio \\
\hline $\begin{array}{l}\text { Leucemia mieloide } \\
\text { aguda con } t(9 ; 11) \\
\text { (p22;q23); MШТ3-KMा2A } \\
{[13,14,27-30]}\end{array}$ & $\begin{array}{l}\text { Alrededor del } \\
15 \% \\
\text { Predominio en } \\
\text { neonatos }\end{array}$ & $\begin{array}{l}\text { Intermedio en } \\
\text { comparación } \\
\text { con otros rear- } \\
\text { reglos del } 11 \text { q23 }\end{array}$ & $\begin{array}{l}\text { Generalmente leucemia } \\
\text { monoblástica o mielo- } \\
\text { monocítica aguda } \\
\text { En ocasiones blastos indif- } \\
\text { erenciados por morfología }\end{array}$ \\
\hline
\end{tabular}

Inmunofenotipo asociado

En niños, expresión de CD33, CD4, CD65, y HLA-DR Expresión disminuida 0 ausente de CD13, CD14 y CD34

\begin{tabular}{|c|c|}
\hline $\begin{array}{l}\text { Leucemia mieloide } \\
\text { aguda t( } 5 ; 11) \\
\text { (q35.3;p15.5); } \\
\text { NUP98-NSD1 } \\
{[13,31,32]}\end{array}$ & $\begin{array}{l}7 \% \\
\text { Mayor frecuen } \\
\text { cia en niños de } \\
\text { edad avanzada } \\
\text { y adolescentes }\end{array}$ \\
\hline $\begin{array}{l}\text { Leucemia mieloide } \\
\text { aguda t }(10 ; 11) \\
\text { (p12;q23.3); KM- } \\
\text { T2A-MLLT10 } \\
{[13,29,33,34]}\end{array}$ & $\begin{array}{l}3,5 \% \\
\text { Predominio en } \\
\text { hombres y en } \\
\text { menores de } 2 \\
\text { años }\end{array}$ \\
\hline
\end{tabular}

Adverso; la Generalmente leucocitomayoría con sis y alto porcentaje de mutaciones aso- blastos

ciadas del gen Subtipo morfológico variFLT3/ITD o del able, principalmente con gen WT1 componente monocítico

\section{Adverso}

Recuento de leucocitos normal o levemente aumentado

Generalmente leucemia monoblástica aguda Rara vez infiltración del sistema nervioso central

Variable, según subtipo morfológico

Variable según subtipo morfológico

En los casos de leucemia monoblástica aguda expresión de CD13, CD33 o ambos, expresión de marcadores monocíticos y CD34 variable

(p15.5;p13.5) NUP98-KDM5A [13,35-37]

Leucemia mieloide aguda con inv(16) (p13.3q24.3); CBFA2T3-GLIS2 $[13,38,39]$

Leucemia mieloide
aguda con $t(6 ; 9)$
(p23;q34); DEK-
NUP214
$[13,40]$

Leucemia mieloide aguda (megacarioblástica) con $\mathrm{t}(1 ; 22)(\mathrm{p} 13 ; \mathrm{q} 13)$; RBM15-MKL1 $[13,41]$ menores de 5 años

$3 \%$

\section{$3 \%$}

Aproximadamente

el $10 \%$ de los casos de leucemia aguda en neonatos Representa el 30\% de los casos de leucemia megacarioblástica aguda en niños sin síndrome de Down

\section{$1 \%$ al $2 \%$}

Edad promedio de presentación: 10 años

Predominio en hombres

Menor del $1 \%$ Mayor frecuencia en neonatos Predominio en mujeres
Variable, según subtipo morfológico

\section{Intermedio}

Generalmente leucemia megacarioblástica aguda, en ocasiones leucemia mieloide aguda con maduración

Generalmente leucemia megacarioblástica aguda, en ocasiones leucemia monoblástica aguda, leucemia mieloide aguda sin maduración y mínimamente diferenciada Cariotipo normal

\begin{tabular}{|c|c|}
\hline Adverso & $\begin{array}{l}\text { Leucemia mieloide aguda } \\
\text { con maduración o leu- } \\
\text { cemia mielomonocítica } \\
\text { aguda, basofilia en sangre } \\
\text { periférica, displasia pre- } \\
\text { dominantemente de series } \\
\text { eritroides y granulocítica }\end{array}$ \\
\hline Intermedio & $\begin{array}{l}\text { Diferenciación megaca- } \\
\text { riocítica }\end{array}$ \\
\hline
\end{tabular}

Variable, según subtipo morfológico 
En los niños la leucemia promielocítica aguda representa alrededor del 10\% de los casos de leucemia mieloide aguda, aunque se observan diferencias geográficas; por ejemplo, en países como Guatemala y Cuba representa aproximadamente el $30 \%$ de todos los casos de leucemia mieloide aguda, mientras que en países como Estados Unidos, Hungría, Alemania, Suiza, entre otros, no superan el $7 \%$ de los casos [47]. Clínicamente, al igual que en los adultos, la leucemia promielocítica aguda representa una emergencia médica ya que tiene una alta mortalidad temprana secundaria a hemorragia o coagulación intravascular diseminada (CID), por lo cual, debe ser identificada y tratada oportunamente ante su sospecha diagnóstica $[45,46]$.

Para el diagnóstico de la leucemia promielocítica aguda el hemograma y el extendido de sangre periférica

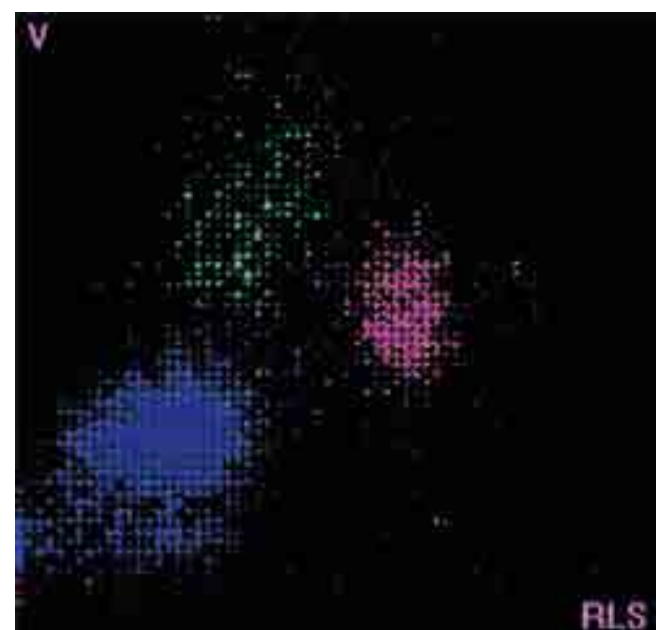

Figura 3. Hemograma de un paciente con leucemia promielocítica aguda PML-RARA en un autoanalizador Coulter $\mathrm{LH}-780 \AA$. En este caso se observa pancitopenia (leucocitos: $1,7 \times 10^{3} / \mu \mathrm{L}$, hemoglobina: 8,0 $\mathrm{g} / \mathrm{dL}$, hematocrito: $22,4 \mathrm{~g} / \mathrm{dL}$, plaquetas: $77 \times 10^{3} /$ $\mu \mathrm{L})$. Obsérvense las alteraciones en la distribución celular en el dispersograma. En el histograma de leucocitos (no mostrado) se observó solamente un pico de población linfoide sin presencia de células intermedias o granulocitos. El equipo alarmó sobre la neutropenia (neutrófilos: $300 / \mu \mathrm{L}$ ) y no alertó sobre la presencia de células inmaduras. Cortesía del Laboratorio Clínico Hospital Universitario de San Vicente Fundación. Medellín, Colombia. resultan claves, ya que la correcta identificación de los promielocitos es lo que suele disparar una alarma clínica para la rápida confirmación del diagnóstico e inicio del tratamiento. En el hemograma no necesariamente se debe esperar la hiperleucocitosis; los casos de más difícil diagnóstico son, de hecho, los leucopénicos (véase figura 3), los cuales requieren la adecuada revisión del extendido e interpretación del hemograma para alertar al médico tratante.

Morfológicamente la leucemia promielocítica aguda tiene dos variantes, hipergranular y microgranular. La variante hipergranular se caracteriza por la presencia de promielocitos con abundantes gránulos azurófilos (gránulos primarios) y algunos de ellos presentan múltiples cuerpos de Auer, en cuyo caso reciben el nombre de células de Faggot o en haz de leña, casi patognomónica de esta enfermedad. Por su parte, la variante microgranular suele representar mayor confusión diagnóstica, pues la mayoría de los promielocitos no poseen gránulos evidentes y pueden ser confundidos con monoblastos o mieloblastos (leucemias mieloides agudas sin maduración), aunque suele haber, en cualquier cantidad, células de Faggot o promielocitos con gránulos azurófilos evidentes $[26,47]$, lo que hace importante la revisión del todo extendido de sangre. 
La variante microgranular suele presentarse con leucopenia, por lo que el reto diagnóstico para los bacteriólogos y microbiólogos es mayor. En este sentido, se recomienda que en aquellos casos de pacientes con leucopenia y trombocitopenia severa, acompañada de neutropenia marcada, se revise rigurosamente el extendido de sangre periférica y se recurra a los datos clínicos y de laboratorio (p. ej. fibrinógeno y dímero D) para un correcto reporte del hemograma. En la figura 4 se presenta la variedad de promielocitos que se pueden observar en el extendido de sangre periférica de un paciente con leucemia promielocítica aguda.

Posterior al hemograma y el establecimiento de una sospecha clínica, se realiza el aspirado de médula ósea, el cual usualmente se observa hipercelular y con presencia de más promielocitos que blastos; los promielocitos típicamente tienen citoplasma abundante, numerosos gránulos y en algunos casos cuerpos de Auer [26]. Por lo general, en el aspirado se hace más evidente la presencia de promielocitos en comparación con el extendido de sangre periférica (véase figura 5).

Con respecto a la citometría de flujo la variante hiperganular se caracteriza por la ausencia o la poca expresión de los marcadores HLA-DR, CD34, CD11a, CD11b, CD15, CD56 y CD18, la expresión homogénea de CD33 y heterogénea de CD13 y la expresión débil de CD117. Por su parte, la variante microgranular presenta expresión débil de CD34 y HLA-DR, expresión homogénea de CD13, heterogénea de CD33 y aberrante de CD2 [26,27]. En la figura 6 se presentan algunos hallazgos por citometría de flujo en un paciente con leucemia promielocítica aguda.

No obstante, para confirmar el diagnóstico se debe realizar un cariotipo, una hibridación fluorescente in situ (FISH; del inglés, Fluorescent In-Situ Hybridization) o una reacción en cadena de la polimerasa transcriptasa reversa (RT-PCR; del inglés, Reverse Transcription Polymerase Chain Reaction) para detectar la alteración característica de esta enfermedad. El cariotipo revela la presencia de la translocación $\mathrm{t}(15 ; 17)(\mathrm{q} 22 ; \mathrm{q} 21)$. Es importante que para la técnica empleada se considere si detecta las translocaciones crípticas, de forma que no se obtenga un falso negativo y una falla en el tratamiento. Por ejemplo, algunas técnicas de RT-PCR empleadas en Colombia sólo detectan la variante bcr1 del gen de fusión PML/RARA, la cual está presente únicamente en el 55\% de los pacientes con leucemia promielocítica aguda. En cuanto al FISH se debe tener en cuenta el tipo de sonda empleado y el tipo de señal emitida.

\section{Leucemia mieloide aguda con t(9;11)(p22;q23); MLLT3-KMT2A}

La leucemia mieloide aguda con $\mathrm{t}(9 ; 11)(\mathrm{p} 22 ; \mathrm{q} 23)$; MLLT3-KMT2AA por lo general se asocia con características monocíticas; en edad pediátrica tiene una frecuencia cercana al $13 \%$ y es más común en los infantes $[13,48-50]$. Se ha observado que 

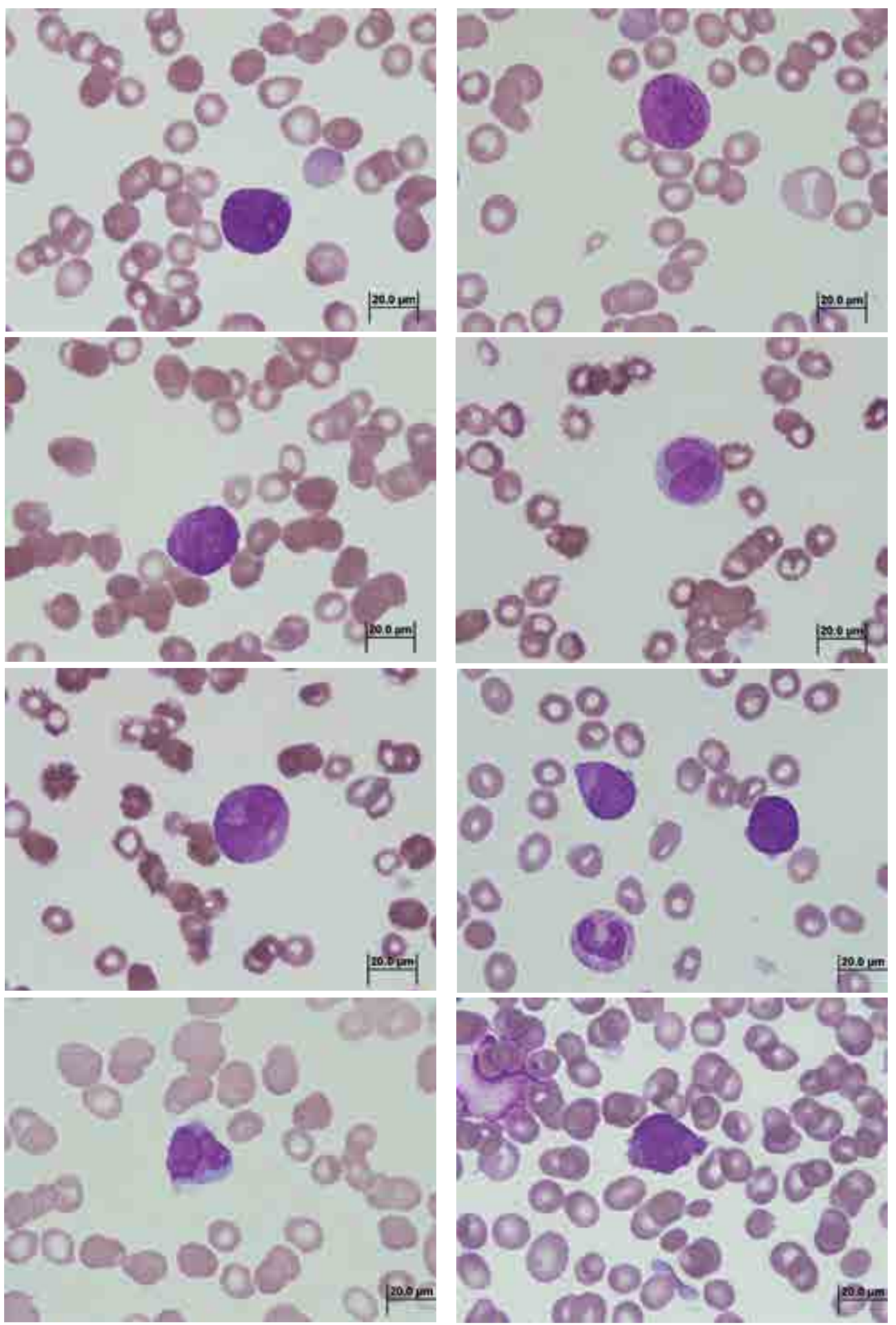

Figura 4. Promielocitos en extendidos de sangre periférica de pacientes con leucemia promielocítica aguda. Obsérvense diferentes promielocitos, algunos microgranulares y otros completamente hipergranulares. Cortesía del Laboratorio Clínico Hospital Universitario de San Vicente Fundación. Medellín, Colombia. 

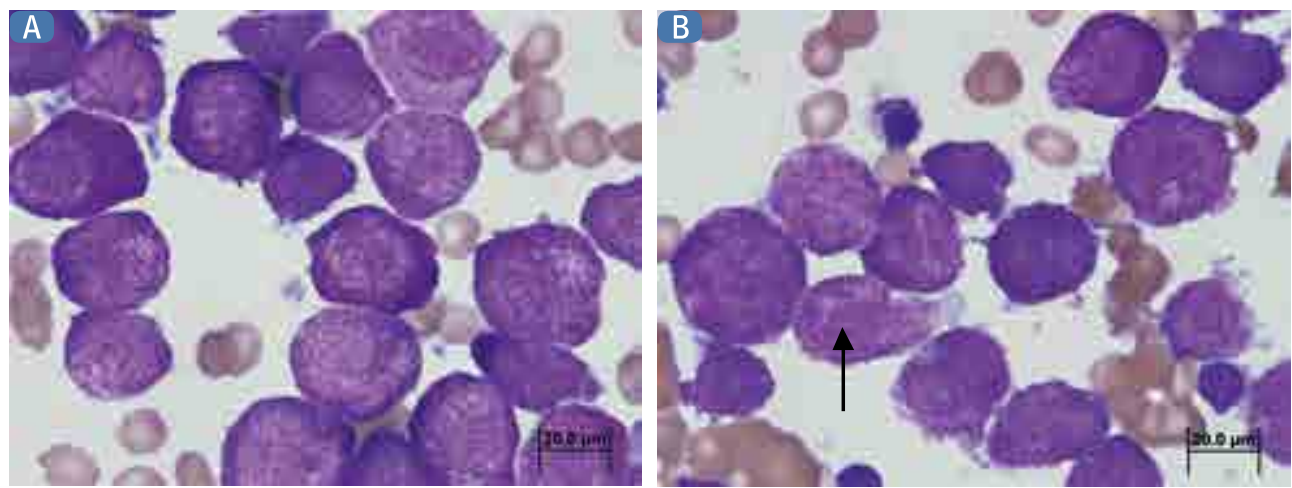

Figura 5. Aspirados de médula ósea de pacientes con leucemia promielocítica aguda. a) Obsérvense las variaciones en los promielocitos, los cuales usualmente tienen más gránulos que en el extendido de sangre periférica. b) Obsérvense promielocitos hipergranulares y célula de Faggot (flecha). Cortesía del Laboratorio Clínico Hospital Universitario de San Vicente Fundación. Medellín, Colombia.

A

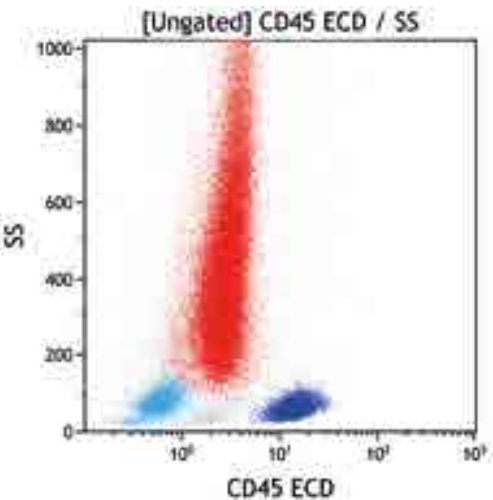

C

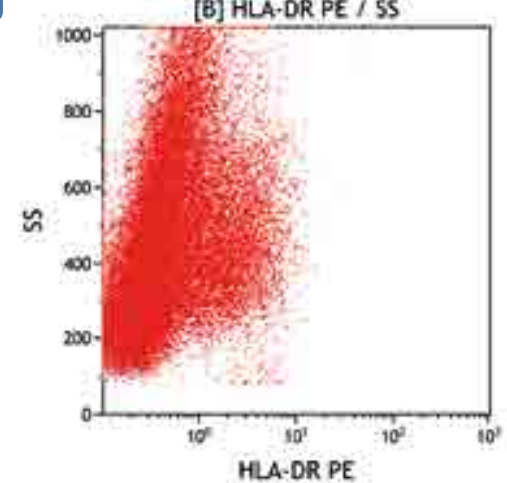

B

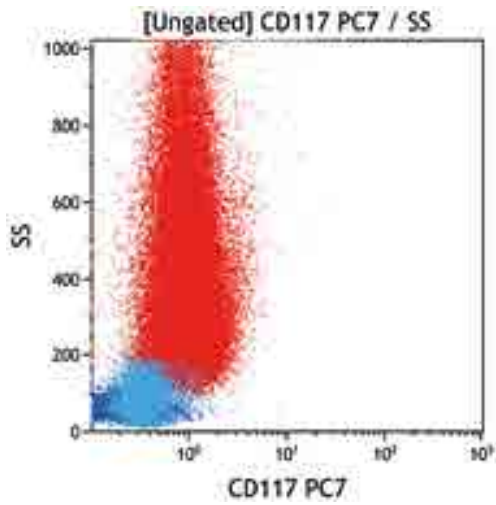

D

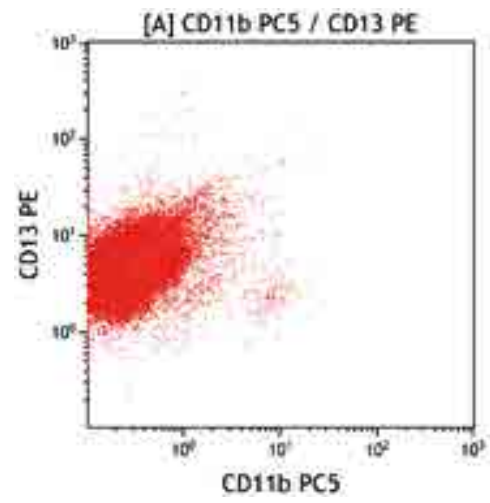

Figura 6. Citometría de flujo de un paciente con leucemia promielocítica aguda. a) Citograma CD45. En rojo se observa la población de promielocitos $(77,5 \%)$, que característicamente forman una gota en la región granulocítica (granulocitos maduros $0,3 \%$ ); en azul oscuro (CD45 fuerte) se observan los linfocitos $(13,2 \%)$ y en azul claro los eritroblastos y los detritos (7,1\%). b) Promielocitos CD117 negativos. C) Promielocitos HLA-DR negativos en su mayoría. d) Promielocitos positivos para CD13 y negativos para CD11b. Obsérvense pocos granulocitos en estados intermedios, lo cual refleja el freno madurativo característico de esta neoplasia. Entre otros hallazgos (no mostrados), se observó la expresión fuerte de CD33 y mieloperoxidasa en los promielocitos, mientras que el CD15 fue característicamente negativo. Cortesía del Laboratorio Clínico Hospital Universitario de San Vicente Fundación. Medellín, Colombia. 
los rearreglos del gen KMT2A (denominado anteriormente MLL) se desarrollan durante la fase prenatal, y por ello, probablemente, las leucemias con mutaciones del gen KMT2A sean más frecuentes en los infantes $[28,51]$.

La traslocación $\mathrm{t}(9 ; 11)(\mathrm{p} 22 ; \mathrm{q} 23)$ implica un gen de fusión entre el gen KMT2A (MLL, HRX) en el locus 11q23 y el gen MLLT3 (AF9) del cromosoma 9. El gen KMT2A codifica la denominada proteína de la leucemia mieloide mixta [26] y se conoce por su alto potencial de translocación, hasta el punto que se han descrito más de 60 translocaciones diferentes $[28,49,52]$.

El $50 \%$ de los niños con leucemia mieloide aguda y con rearreglos del gen KMT2A tienen la $\mathrm{t}(9 ; 11)(\mathrm{p} 22 ; \mathrm{q} 23)$; MLLT3-KMT2A, mientras que en los casos restantes la translocación ocurre principalmente con los genes MLLT10, MLLT4, ELL, MLLT1, MLLT11, AFF1, ABI1 y MLLT6, entre otros. Estas translocaciones alternativas tienen un comportamiento biológico, clínico y pronóstico diferente al de la translocación con el gen MLLT3 [29,53]. Para detectar los rearreglos del gen KMT2A se pueden emplear algunas sondas comerciales para FISH y, en algunos casos, recurrir a la RT-PCR [54,55].

Si bien el pronóstico de la leucemia mieloide aguda con $\mathrm{t}(9 ; 11)(\mathrm{p} 22 ; \mathrm{q} 23)$; MLLT3-KMT2A ha mejorado con el uso de algunos agentes quimioterapéuticos, en esta leucemia hay un alto riesgo de coagulación intravascular disemina$\mathrm{da}$, presencia de lesiones en piel (sarcoma mieloide), alta carga tumoral (leucocitosis, organomegalia, o ambas), riesgo de infiltración al sistema nervioso central y desarrollo de alteraciones citogenéticas adicionales al rearreglo del $11 q 23[28,29,50,52]$. Por lo anterior, es importante que en niños con leucemias de linaje monocítico el estudio se complemente con un cariotipo y un FISH específico para la búsqueda de alteraciones del gen KMT2A.

Las características morfológicas de este subtipo de leucemia incluyen predominio de monoblastos y promonocitos. Los monoblastos son células grandes, con abundante citoplasma, basofilia variable, gránulos azurófilos finos, vacuolas y en algunos casos presencia de seudópodos; además, por lo general tienen núcleos redondos con cromatina fina y delicada. Los promonocitos, por su parte, tienen un contorno nuclear más irregular y el citoplasma es menos basófilo y más granular (véase figura 7).

En cuanto al inmunofenotipo en niños con leucemia mieloide aguda con $\mathrm{t}(9 ; 11)$ (p22;q23); MLLT3-KMT2A generalmente se observa una expresión fuerte de CD33, CD64, CD4 y HLA-DR, mientras que la expresión de CD13, CD34 y CD14 es generalmente débil o negativa (véase figura 8). También se puede detectar el antígeno NG2 (reconocido por citometría de flujo mediante el anticuerpo monoclonal 7.1), el cual está presente característicamente en las leucemias con alguna de las translocaciones del gen $\operatorname{KMT2A}[27,56]$. 

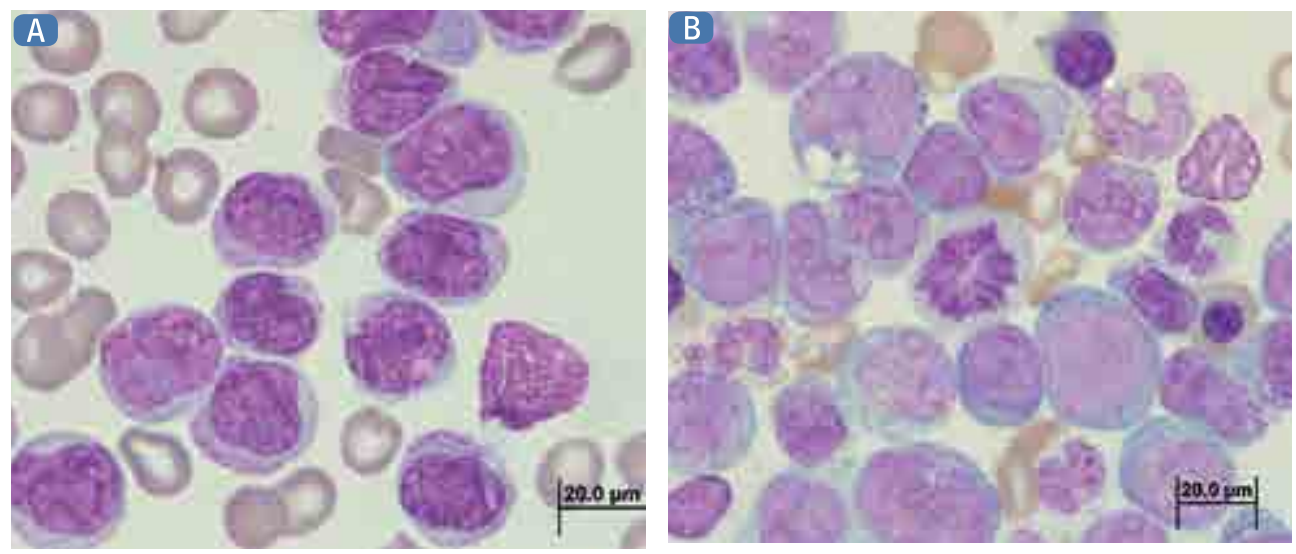

Figura 7. Características morfológicas de la leucemia mieloide aguda con $\mathrm{t}(9 ; 11)(\mathrm{p} 22 ; \mathrm{q} 23)$; MLLT3-KMT2A. a) Extendido de sangre periférica en el que predomina el linaje monocítico. b) Aspirado de médula ósea, con predominio de la serie monocítica inmadura, acompañada de población mieloide y eritroide residual. En el cariotipo del paciente (no mostrado) se destacaron los siguientes hallazgos: $46, \mathrm{XX}, \mathrm{t}(9 ; 11)$ (p22;q23) y 46,XX. Cortesía del Laboratorio Clínico Hospital Universitario de San Vicente Fundación. Medellín, Colombia.

\section{Leucemia mieloide aguda con mutaciones génicas}

Las leucemias mieloides agudas con mutaciones génicas hacen referencia principalmente a aquellos casos que presentan un cariotipo normal pero en los que, mediante pruebas moleculares, se detectan mutaciones específicas de genes como FLT3, CEBPA (del inglés, CCAAT/enhancer binding protein-a), WT1 (gen del tumor de Wilms) y NPM1 (nucleofosmina), entre otros $[30,57]$. En la actualización de la clasificación de la OMS de 2016 las siguientes mutaciones se consideran un subtipo de leucemia: leucemia mieloide aguda con mutaciones de NPM1, leucemia mieloide aguda con mutaciones bialélicas de CEBPA y leucemia mieloide aguda con mutación RUNX1 (entidad provisional) $[13,58]$.

Las mutaciones de NPM1 se presentan en aproximadamente el $20 \%$ de niños con cariotipo normal. Cuando no se observan otras mutaciones génicas (por ejemplo mutaciones FLT3), las mutaciones del gen NPM1 confieren buen pronóstico. El gen NPM1 está localizado en el cromosoma 5 (5q3) y codifica para una chaperona molecular con funciones en el paso de moléculas del núcleo al citoplasma, la biogénesis ribosomal y la regulación de la vía supresora de tumores AF3-TP53, entre otras funciones. Las mutaciones en NPM1 son muy estables, confieren una buena respuesta a la terapia y supervivencia a cinco años; además, fenotípicamente se asocia con la leucemia mielomonocítica aguda y la monocítica aguda $[30,59,60]$. 

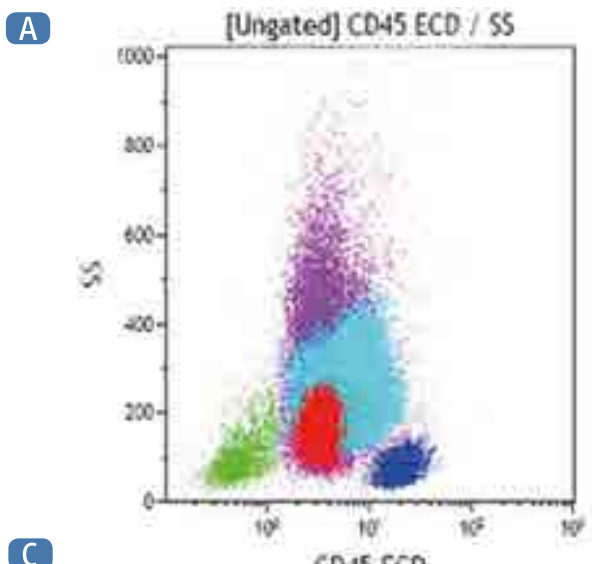

CD $45 \mathrm{ECO}$

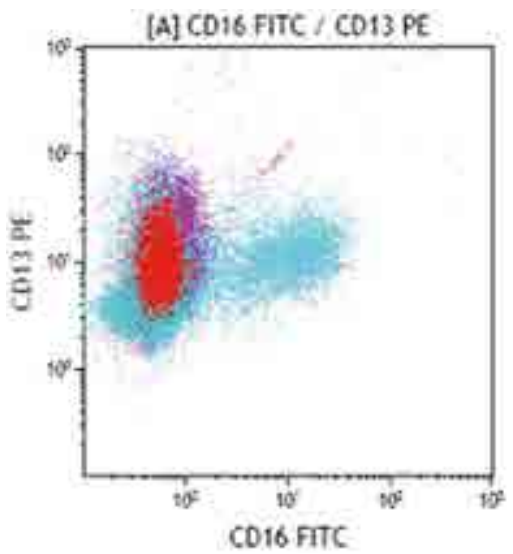

B

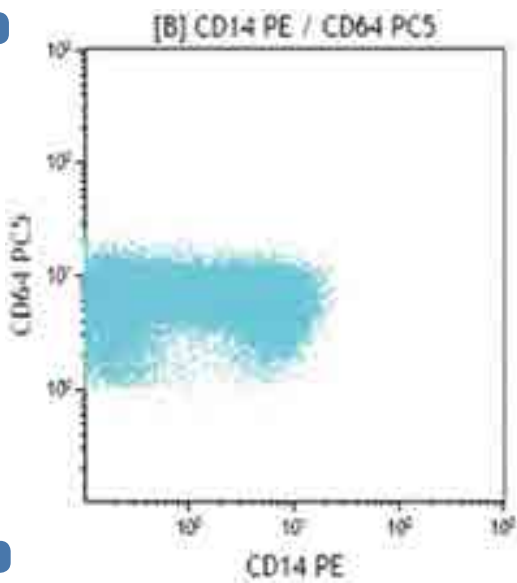

D

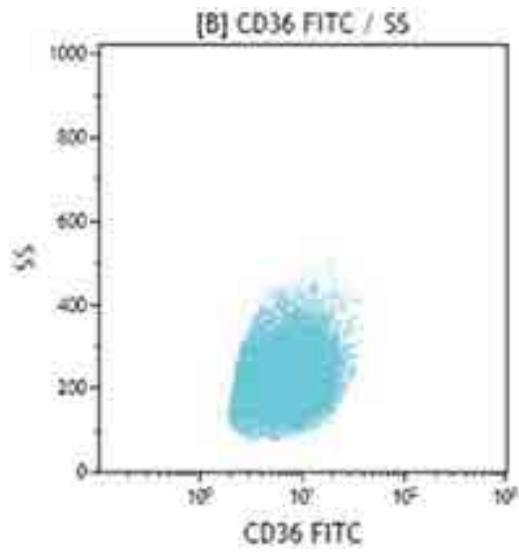

Figura 8. Citometría de flujo del paciente con leucemia mieloide aguda con t(9;11)(p22;q23); MLLT3-KMT2A presentado en la figura 7. a) Citograma CD45. En rojo se observa la población mieloide inmadura $(9,9 \%)$, en morado la población granulocítica en distintos estados de maduración $(2,5 \%)$, en azul claro la población monocítica en distintos estados de maduración $(69,4 \%)$, en azul oscuro los linfocitos $(4,9 \%)$ y en verde los eritroblastos 3,3\%). b) Población monocítica en distintos estados de maduración de acuerdo con la expresión de CD14 y CD64. c) Estados de maduración en la población granulocítica y monocítica con base en la curva de maduración CD16/CD13. d) Expresión de CD36 en el componente monocítico. Otros hallazgos (no mostrados) en la población neoplásica tuvo expresión de CD15+, CD11b+, CD33+ y HLA-DR+ heterogéneo. Cortesía del Laboratorio Clínico Hospital Universitario de San Vicente Fundación. Medellín, Colombia.

CEBPA es un factor de transcripción fundamental en estados tempranos de la diferenciación mieloide. Las mutaciones en CEBPA se asocian principalmente con la leucemia mieloide aguda sin maduración y la leucemia mieloide aguda con maduración; en ambos casos, las mutaciones de CEBPA se relacionan con un pronóstico favorable. Los pacientes con estas mutaciones presentan concentraciones altas de hemoglobina, recuentos plaquetarios disminuidos, altos recuentos blásticos y difícilmente tienen linfadenopatías o leucemia extramedular comparados con los pacientes sin mutaciones [61,62]; no obstante, su identificación y diagnóstico sólo se logra mediante el uso de herramientas moleculares. 
Por su parte, el gen RUNX1 por lo general se relaciona con la t( $8 ; 21)(q 22 ; q 22.1)$; no obstante, en la revisión de 2016 de la OMS las mutaciones de RUNX1 en pacientes con cariotipo normal o sin dicha translocación se convirtieron en un subtipo de leucemia mieloide aguda. Entre las funciones de RUNX1 se destaca su acción como regulador transcripcional de genes que codifican para factores de crecimiento, receptores de membrana, moléculas de señalización y activadores transcripcionales, por lo que se considera que RUNX1 tiene fuerte influencia en la hematopoyesis y el adecuado desarrollo celular [63].

Las mutaciones de RUNX1 tienen una frecuencia variable (entre 5\% y $26 \%$ ) en los pacientes con leucemia mieloide aguda de cariotipo normal; además, tienen un efecto adverso negativo, atribuido a las menores tasas de supervivencia total, remisión completa y supervivencia libre de enfermedad respecto a quienes no presentan dichas mutaciones [63-65], que no es influenciado por el estado mutacional de FLT3 u otros genes que confieren mal pronóstico [63]. No obstante, algunos autores plantean que la proteína de fusión aislada no es suficiente para el desarrollo de la leucemia y se requiere de eventos posteriores de carácter epigenético para que se presente $[66,67]$.

Por su parte, WT1 es un factor de transcripción involucrado en el metabolismo y crecimiento celular, que está sobreexpresado en la mayoría de los pacientes con leucemia mieloide aguda; su estado mutacional varía entre las diferentes formas de leucemia y su significado pronóstico es controvertido. En algunos estudios se ha descrito una menor tasa de remisión completa y supervivencia y mayor riesgo de recaída en los pacientes con estas mutaciones [68,69], mientras que en otros sólo se ha observado un pronóstico desfavorable cuando la mutación de WT1 se asocia a la mutación FLT3-ITD [70,71].

Para finalizar, el FLT3 es un receptor de tirosina quinasa, importante en la supervivencia, la diferenciación y la proliferación celular [72]. Este gen se encuentra mutado aproximadamente en el $10 \%$ de niños con leucemia mieloide aguda [73], ya sea por duplicaciones en tándem internas (ITD; del inglés, internal tandem duplications) del módulo yuxtamembrana o por mutaciones puntuales que casi siempre afectan el dominio quinasa (KD) [74].

La mutación en FLT3 no fue incluida como una entidad independiente en la clasificación de la OMS, debido a que se presenta en varios subtipos de leucemia mieloide aguda; sin embargo, su significancia no debe ser subestimada ya que su identificación en pacientes con cariotipo normal o con alguna anormalidad cromosómica puede establecer el pronóstico de la leucemia en el paciente pediátrico. Por lo general, las mutaciones del FLT3 (FLT3-ITD) están relacionadas con pronóstico adverso, bajas tasas de curación y alto riesgo de recaídas, por lo que han adquirido gran relevancia en las decisiones de tratamiento [74-76]. 
En cohortes pediátricas se ha observado que la detección molecular de altos niveles de FLT3-ITD después del primer ciclo de quimioterapia predicen una baja supervivencia libre de enfermedad, por lo que se sugiere que el seguimiento molecular de esta mutación haga parte del esquema de evaluación del paciente durante la quimioterapia y ayude a definir los posibles cambios en el tratamiento [77].

En la actualidad, una de las líneas de investigación en leucemias es el desarrollo de medicamentos dirigidos específicamente a regular los mecanismos fisiopatogénicos implicados en la leucemia mieloide aguda $[7,78]$; así, los perfiles de expresión genética permitirían definir un tratamiento más personalizado y predecir qué medicamentos son los más eficaces para cada paciente. En este sentido, a pesar de que las mutaciones descritas no se evalúan de rutina en Colombia ni están disponibles en la mayoría de centros de diagnóstico y tratamiento de leucemias pediátricas, es importante tenerlas presentes, pues quizá son la próxima generación de pruebas moleculares que se deban ofrecer y realizar en el país para el adecuado diagnóstico y, principalmente, pronóstico de los pacientes con leucemia mieloide aguda.

\section{Leucemias mieloides agudas no clasificables en otra categoría}

Las leucemias mieloides agudas no clasificables en otra categoría agrupa principalmente la antigua clasificación FAB y la base para su clasificación son las características morfológicas, citoquímicas e inmunofenotípicas de las células leucémicas, indicando las líneas celulares implicadas y su grado de maduración. En esta categoría se incluyen las leucemias que no se pueden clasificar en otros grupos, o las de aquellos pacientes a quienes no se les puede realizar estudios citogenéticos o moleculares y que, por lo tanto, no se les demuestra que presentan una alteración genética recurrente. Para el diagnóstico de una de estas entidades se requiere el hallazgo de más del $20 \%$ de blastos en sangre periférica o médula ósea $[13,79]$. A continuación se citan las leucemias mieloides agudas no clasificables en otras categorías que fueron incluidas en la actualización de la clasificación de la OMS [13]:

- Leucemia mieloide aguda con mínima diferenciación

- Leucemia mieloide aguda sin maduración

- Leucemia mielomonocítica aguda

- Leucemia monocítica/monoblástica aguda

- Leucemia eritroide pura 
- Leucemia megacarioblástica aguda

- Leucemia basofílica aguda

- Panmieloisis aguda con mielofibrosis

Respecto a la clasificación de 2008 de la OMS, uno de los principales cambios de la actualización de 2016 reside en la leucemia eritroide aguda, ya que inicialmente se reconocían dos subtipos: la eritroleucemia y la leucemia eritroide pura, las cuales se diferenciaban principalmente en el recuento de blastos mieloides. La eritroleucemia se definía como la presencia de más del $50 \%$ de precursores eritroides con respecto a toda la población nucleada y el $20 \%$ o más de mieloblastos con respecto a la población no eritroide, mientras que la leucemia eritroide pura incluía más del $80 \%$ de eritroblastos de predominio inmaduro sin aumento de mieloblastos [79].

Debido a las variaciones en el tratamiento y el comportamiento clínico-biológico de estas entidades, aquellos casos que antes se denominaban eritroleucemia se deben evaluar adecuadamente y clasificar dentro de uno de los subtipos de síndrome mielodisplásicos; entretanto, la leucemia eritroide pura se considera el único tipo de leucemia mieloide aguda de linaje eritroide y continúa en el grupo de aquellas no clasificables en otras categorías [13].

Las leucemias mieloides agudas no clasificables en otras categorías más frecuentes en niños son la leucemia mieloide aguda con mínima diferenciación (predominio en infantes), la leucemia mieloide aguda con maduración y la leucemia monoblástica aguda; no obstante, cualquier subtipo puede afectar a la población pediátrica $[4,79]$. En la tabla 4 se detallan los principales hallazgos de laboratorio para cada subtipo de leucemias mieloides agudas no clasificables en otra categoría.

En general, entre los principales hallazgos en el extendido de sangre periférica en las leucemias mieloides agudas no clasificables en otra categoría se destacan la presencia de blastos en cantidad variable, la trombocitopenia y la anemia. Respecto a los blastos, su morfología varía dependiendo del subtipo; por ejemplo, en la leucemia mieloide aguda con mínima diferenciación los blastos pueden simular linfoblastos, pues no presentan gránulos ni cuerpos de Auer (véase figura 9) y en la leucemia mieloide aguda sin maduración la cantidad de blastos en sangre periférica es variable y por lo general tienen gránulos o cuerpos de Auer. En los demás subtipos los hallazgos varían de acuerdo con lo descrito en la tabla 4.

Se debe enfatizar en que la única característica morfológica que es propia del mieloblasto es el cuerpo de Auer, por lo que siempre se debe esperar hasta 


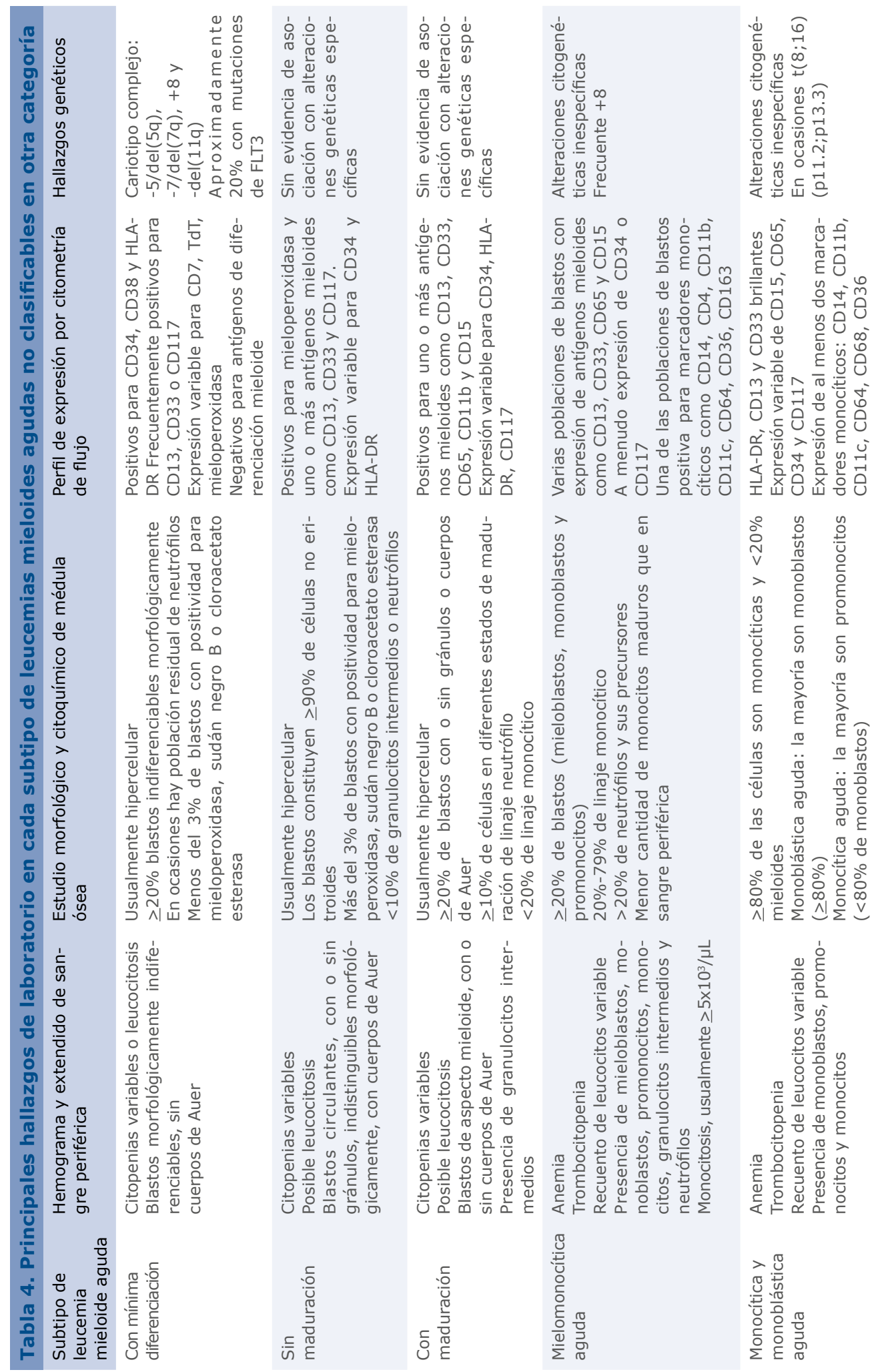




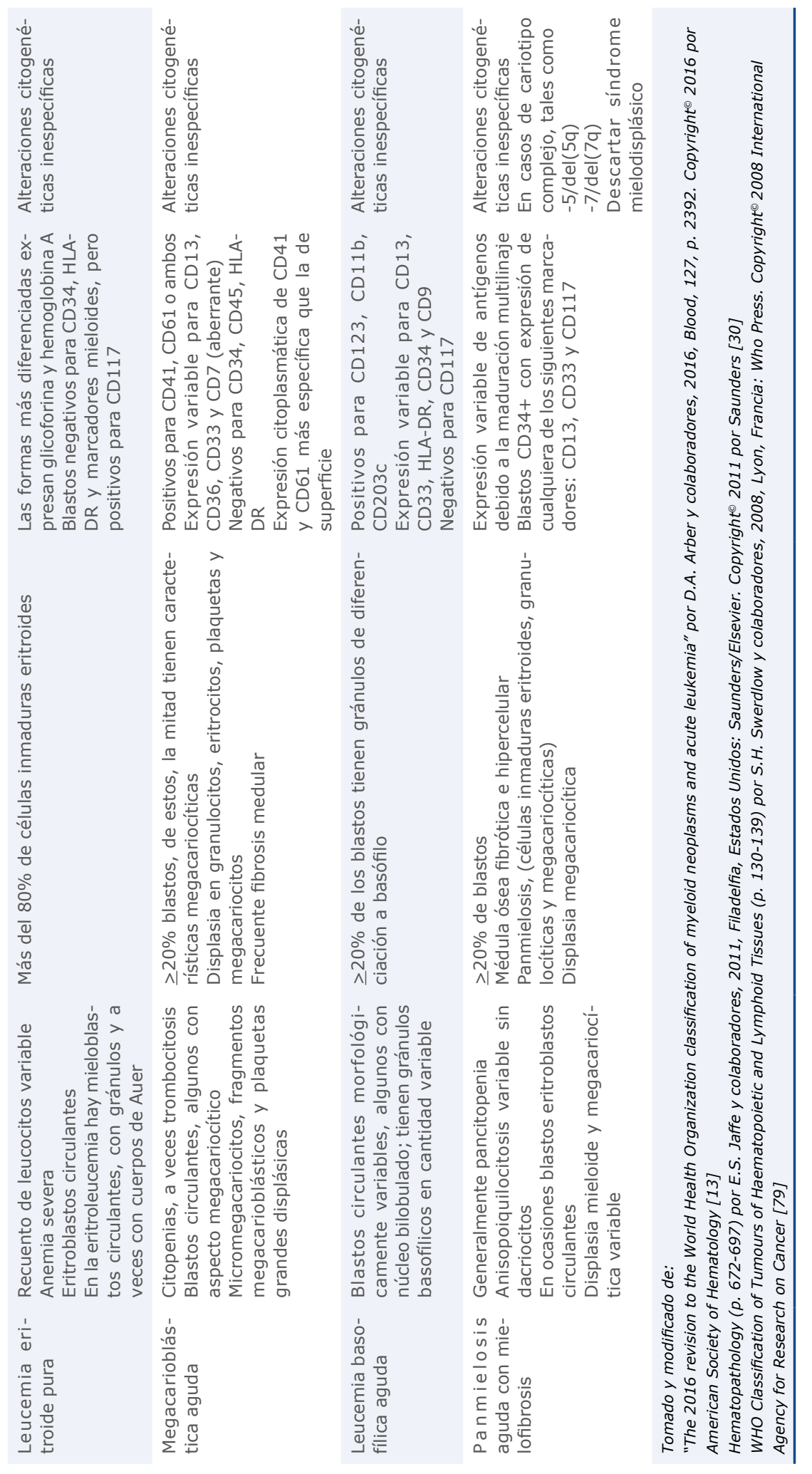

Medicina \& Laboratorio / Volumen 22, Números 3-4, 2016. 

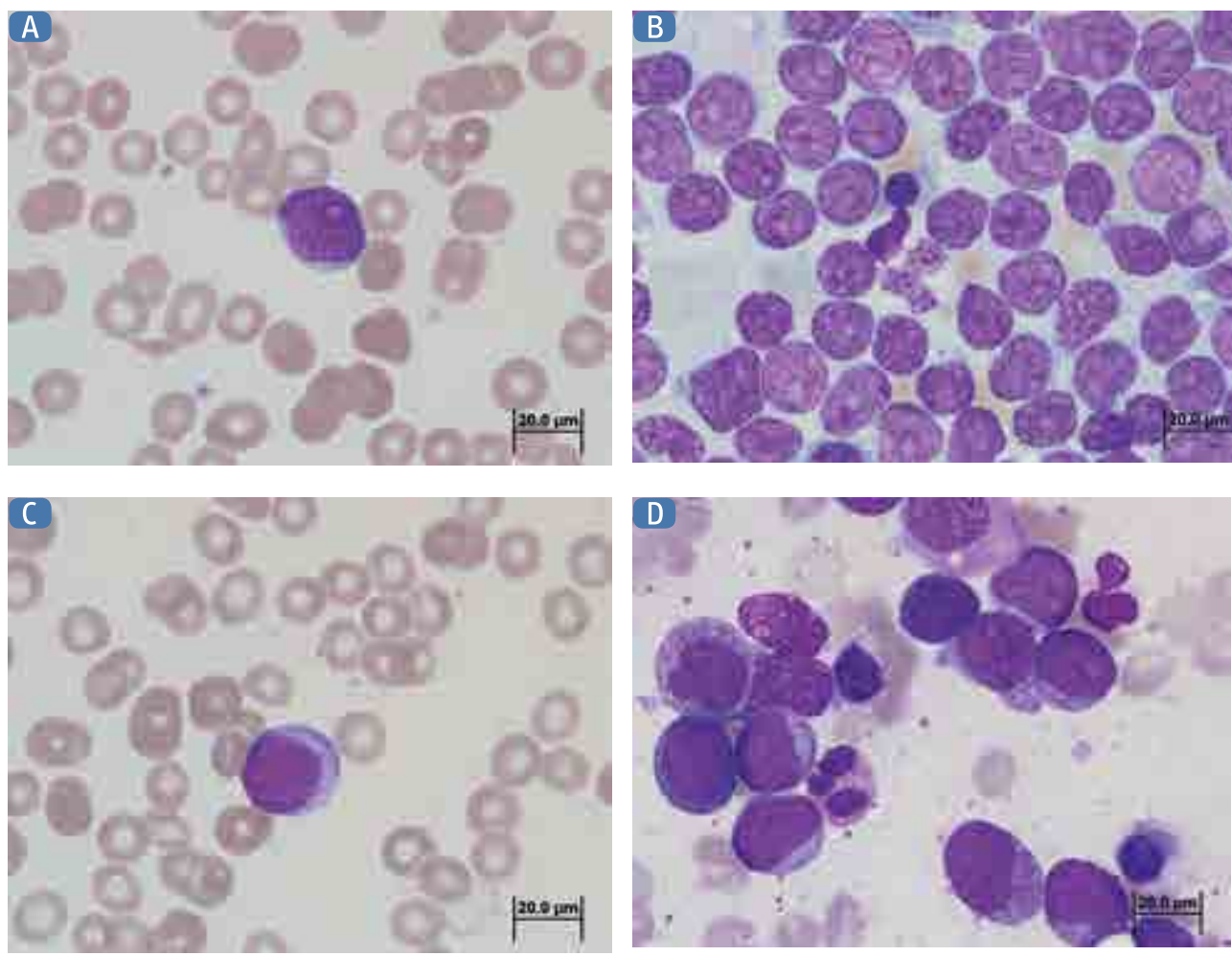

Figura 9. Hallazgos morfológicos en leucemias mieloides agudas no clasificables en otras categorías. a) Extendido de sangre periférica de una leucemia mieloide aguda con mínima diferenciación, con presencia de un blasto morfológicamente indiferenciable entre un mieloblasto y un linfoblasto. b) Aspirado de médula ósea del paciente de la figura 9a (leucemia mieloide aguda con mínima diferenciación), con presencia de más de $90 \%$ de blastos heterogéneos, morfológicamente indiferenciables de linfoblastos. c) Extendido de sangre periférica de una leucemia mieloide aguda sin maduración, en la cual se observan cuerpos de Auer. d) Aspirado de médula ósea leucemia mieloide aguda con maduración, en la que se observan granulocitos intermedios y mieloblastos, algunos con cuerpos de Auer. Cortesía del Laboratorio Clínico Hematológico. Medellín, Colombia.

la biopsia, la citometría de flujo o ambas para definir si se trata de una leucemia mieloide aguda. En relación con el aspirado medular (mielograma) los hallazgos también varían según lo descrito en la tabla 4; por lo general, el recuento de blastos es mayor en médula ósea respecto a la sangre periférica.

\section{Proliferaciones mieloides relacionadas con síndrome de Down}

Los pacientes con síndrome de Down tienen mayor predisposición a desarrollar trastornos hematopoyéticos; a menudo presentan macrocitosis, recuentos anormales de plaquetas y mayor riesgo de desarrollar leucemia $[24,80]$. Al nacimiento, o días después de nacer, alrededor del $10 \%$ de los neonatos con síndrome de Down cursan con mielopoyesis anormal transitoria, un estado preleucémico que en la mayoría de los casos se resuelve espontáneamente uno o dos meses después; no obstante, el $30 \%$ de ellos pueden progresar a leucemia 
megacarioblástica aguda. De igual manera, cualquier niño con síndrome de Down puede desarrollar dicha leucemia [46,81-84]. En la tabla 5 se resumen las características de las principales alteraciones hematológicas en niños con síndrome de Down [85].

\begin{tabular}{|c|c|c|c|c|}
\hline \multirow[b]{2}{*}{ Enfermedad } & \multicolumn{4}{|c|}{ Característica } \\
\hline & Epidemiología & Pronóstico & $\begin{array}{l}\text { Hallazgos } \\
\text { de laboratorio }\end{array}$ & $\begin{array}{l}\text { Inmunofenotipo } \\
\text { asociado }\end{array}$ \\
\hline $\begin{array}{l}\text { Anormalidades } \\
\text { transitorias } \\
\text { del recién } \\
\text { nacido }\end{array}$ & $\begin{array}{l}\text { Neutrofilia } 80 \% \\
\text { Trombocitopenia } \\
66 \% \\
\text { Policitemia } 33 \%\end{array}$ & Regresión espontánea & $\begin{array}{l}\text { Neutrofilia, tromboci- } \\
\text { topenia o policitemia }\end{array}$ & $\begin{array}{l}\text { No se realiza de } \\
\text { rutina }\end{array}$ \\
\hline $\begin{array}{l}\text { Mielopoyesis } \\
\text { anormal } \\
\text { transitoria }\end{array}$ & $\begin{array}{l}3 \% \text { al } 10 \% \\
\text { Mediana de } \\
\text { edad a los siete } \\
\text { días de nacido }\end{array}$ & $\begin{array}{l}\text { Remisión completa } \\
\text { dentro de los tres me- } \\
\text { ses siguientes en el } \\
60 \% \text { de los casos } \\
\text { En el } 20 \% \text { se requie- } \\
\text { ren dosis bajas de } \\
\text { citarabina } \\
\text { Muerte temprana en } \\
\text { el } 15 \% \text { al } 20 \% \text { de los } \\
\text { casos }\end{array}$ & $\begin{array}{l}\text { Hiperleucocitosis con } \\
\text { blastos megacariocí- } \\
\text { ticos, anemia, trom- } \\
\text { bocitopenia, presen- } \\
\text { cia de eritroblastos, } \\
\text { plaquetas gigantes y } \\
\text { fragmentos de mega- } \\
\text { cariocitos }\end{array}$ & $\begin{array}{l}\text { Expresión de CD33, } \\
\text { CD38, CD117, CD34, } \\
\text { CD7, CD36, CD71, } \\
\text { y CD42b, expresión } \\
\text { débil de CD4 y ex- } \\
\text { presión variable de } \\
\text { CD13, CD56, TPO-R } \\
\text { y R-EPO }\end{array}$ \\
\hline $\begin{array}{l}\text { Leucemia } \\
\text { mieloide } \\
\text { aguda del } \\
\text { síndrome } \\
\text { de Down }\end{array}$ & $\begin{array}{l}\text { Se presenta } \\
\text { principalmente } \\
\text { en menores de } \\
\text { cinco años }\end{array}$ & $\begin{array}{l}\text { Pronóstico favorable } \\
\text { Supervivencia a largo } \\
\text { plazo del } 80 \%\end{array}$ & $\begin{array}{l}\text { Previa mielodispla- } \\
\text { sia, caracterizada } \\
\text { por trombocitopenia } \\
\text { y fibrosis de médula } \\
\text { ósea que puede durar } \\
\text { varios meses } \\
\text { Recuento más bajo de } \\
\text { leucocitos }\end{array}$ & $\begin{array}{l}\text { Expresión de CD33, } \\
\text { CD38, CD117, CD34, } \\
\text { CD7, CD 36, CD71 } \\
\text { y CD42b, expresión } \\
\text { débil de CD4 y ex- } \\
\text { presión variable de } \\
\text { CD13, CD56, TPO-R } \\
\text { y R-EPO }\end{array}$ \\
\hline
\end{tabular}

Tomada y modificada de "Hematological disorders and leukemia in children with Down syndrome" por A. Bruwier y C.F. Chantrain, 2012, Eur J Pediatr, 171, p. 1302. Copyright ${ }^{\odot} 2011$ por Springer-Verlag [85]

Aunque en la mayoría de los casos de mielopoyesis anormal transitoria existen síntomas clínicos leves de hiperleucocitosis, trombocitopenia, anemia o hepatomegalia, algunos pacientes presentan síntomas clínicos graves y potencialmente mortales, como pancitopenia o infiltración a órganos [24]. Las leucemias mieloides agudas en el síndrome de Down presentan características clínicas y biológicas diferentes a las del resto de la población infantil; se caracterizan por su diferenciación principalmente megacariocítica, una edad de presentación con un pico de máxima incidencia antes de los tres años y antecedente de síndrome mielodisplásico $[81,86]$; además, no siempre se encuentra más del $20 \%$ de blastos en médula ósea, lo cual dificulta el diagnóstico.

La morfología de los blastos y el inmunofenotipo por citometría de flujo son muy similares tanto en la leucemia como en la mielopoyesis transitoria y se caracterizan por la expresión de características eritroblásticas y megacario- 
blásticas. El inmunofenotipo se caracteriza por la expresión de CD33, CD38, CD117, CD34, CD7, CD36, CD71 y CD42b, expresión débil de CD4 y expresión variable de CD13, CD56, TPO-R (receptor de trombopoyetina) y R-EPO (receptor de eritropoyetina) $[87,88]$.

En cuanto a las alteraciones moleculares, en ambas entidades se han descrito tanto mutaciones en el gen GATA-1, el cual codifica para un factor de activación de la transcripción que resulta crítico para el normal desarrollo de las ontogenias eritroide y megacariocítica, como alteraciones de la vía celular JAK-STAT $[89,90]$. Respecto al tratamiento y pronóstico, debido a que estos pacientes tienen una mayor sensibilidad a los medicamentos, obtienen mejores resultados después de la quimioterapia en comparación con los pacientes sin este síndrome genético $[46,87,91]$.

\section{Conclusiones}

Las leucemias agudas pediátricas son un evento de interés en salud pública y deben ser objeto de intervenciones que contribuyan a mejorar la oportunidad en el diagnóstico y el acceso a herramientas de laboratorio para un adecuado pronóstico, seguimiento y tratamiento de la enfermedad. Al ser un evento de interés en salud pública, las instituciones prestadoras de servicios de salud se convierten en el pilar para notificar oportunamente la ocurrencia de leucemias agudas pediátricas, lo cual facilita tanto el análisis estadístico por parte de las organizaciones nacionales como, en el mejor de los casos, el desarrollo de políticas de salud con base en las necesidades de cada población.

Los hallazgos en el hemograma y el extendido de sangre periférica permiten sospechar la presencia de una leucemia aguda; por lo que es menester del profesional del laboratorio identificarlos y ser un ente activo en la toma de decisiones y el diagnóstico oportuno de la enfermedad. La experticia del observador y una revisión minuciosa del extendido minimizan el riesgo de falsos negativos, por lo que cada laboratorio debe estandarizar su proceso y establecer los parámetros cuantitativos y cualitativos para su revisión. Se debe tener presente, en todos los procesos, que es responsabilidad de los laboratorios la entrega de resultados confiables, oportunos y de utilidad clínica, de forma que no se afecte el diagnóstico de los pacientes y, de paso, su supervivencia.

En este sentido, el diagnóstico de la leucemia pediátrica, con participación activa del laboratorio clínico, depende de un trabajo interdisciplinario donde convergen profesionales de diferentes áreas del conocimiento y se utilizan pruebas diagnósticas simples y otras más complejas como la citometría de flujo, la biología molecular y la citogenética; todo esto en busca de un diagnóstico idóneo y oportuno que minimice la mortalidad por esta enfermedad. 
Para ello, la Organización Mundial de la Salud, en conjunto con expertos internacionales, ha homogenizado los criterios para la clasificación y el diagnóstico de las neoplasias hematolinfoides, de forma que, con base en todas las pruebas diagnósticas disponibles y las manifestaciones clínicas, se logre un diagnóstico, pronóstico y tratamiento adecuado para cada paciente. No obstante, no todas las herramientas diagnósticas están al alcance en nuestro medio, por lo que se requiere una adecuada interpretación y uso racional de las técnicas disponibles para lograr la clasificación y estadificación más acertada de los pacientes.

Con respecto a su diagnóstico en Colombia, es de resaltar la estandarización y homogenización de conceptos que se ha logrado en muchos centros diagnósticos, en especial, en el diagnóstico y seguimiento por citometría de flujo, la cual es quizá un modelo de lo que en un futuro, ojalá cercano, se debe lograr con las herramientas de citogenética y biología molecular (p. ej. cariotipo, FISH, RT-PCR, secuenciación, entre otras), ya que el pronóstico de los pacientes está ligado estrechamente a las alteraciones genéticas que presenta.

La leucemia es una enfermedad heterogénea $y$, especialmente, la mieloide aguda se caracteriza por su amplia diversidad genética, pronóstica y de tratamiento; por esta razón, los pacientes con diagnósticos aparentemente muy similares desde un punto de vista clínico pueden responder de manera muy diferente al tratamiento. Además, a esta heterogeneidad tumoral hay que sumar la propia heterogeneidad genética del individuo que puede condicionar la eficacia del tratamiento [92].

A pesar de los grandes avances en la caracterización genética y molecular de la leucemia mieloide aguda existen todavía muchas preguntas que esperan respuesta. En los últimos años se ha producido un notable progreso en el conocimiento de su patogénesis molecular; sin embargo, algunas de las alteraciones genéticas relacionadas son todavía desconocidas. Los estudios de secuenciación y epigenética han abierto el camino para el análisis de gran cantidad de genes y sus mutaciones; no obstante, aún se requiere vislumbrar entre aqueIlas que controlan los procesos celulares claves de la leucemia mieloide aguda y que, según el comportamiento epidemiológico de dicha enfermedad en nuestra población, ofrezcan beneficios en supervivencia y calidad de vida a nuestros pacientes.

Además, otros estudios como los de epigenética, proteómica y microRNA contribuyen a identificar los mecanismos de la leucemogénesis, así como las dianas terapéuticas que llevarán al desarrollo de nuevos tratamientos más precisos [57]. El entendimiento del rol que desempeñan estás mutaciones debe proveer las bases para el desarrollo de mejores y más específicas herramientas diagnósticas que, sin perder de vista el contexto económico y tecnológico del país, permitan cada vez más estar al alcance de la población vulnerable. 
En conclusión, las leucemias agudas pediátricas, en especial las leucemias mieloides agudas, son enfermedades heterogéneas que, por su alto impacto en morbilidad y mortalidad, se han constituido como un evento de interés en salud pública para el país; por ello, todos los actores involucrados en el diagnóstico, tratamiento y seguimiento de los pacientes deben trabajar de forma oportuna y articulada, tomando como base la clasificación de la Organización Mundial de la Salud y haciendo un uso racional de las herramientas diagnósticas de las que se disponen en el país.

\section{Bibliografía}

1. Ferlay J, Soerjomataram I, Ervik M, Dikshit R, Eser S, Mathers $C$, et al. Globocan 2012: Estimated Cancer Incidence, Mortality and Prevalence Worldwide in 2012. Organización Mundial de la Salud, International Agency for Research on Cancer. 2012. Disponible: http://globocan.iarc.fr/old/age-specific_table_r.asp ?selection $=40170 \&$ title $=$ Colombia $\&$ sex $=0$ \&type $=1 \&$ stat $=0 \&$ window $=1 \&$ sort $=0 \&$ su bmit=\%C2\%A0Execute, http://globocan. iarc.fr/old/age-specific_table_r.asp?selec tion $=40170 \&$ title $=$ Colombia\&sex $=0$ \&type $=0 \&$ stat $=0$ \&window $=1 \&$ sort $=0$ \&submit $=$ \%C2\%A0Execute. Consultado: ago 2015.

2. Yamamoto JF, Goodman MT. Patterns of leukemia incidence in the United States by subtype and demographic characteristics, 1997-2002. Cancer Causes Control 2008; 19: 379-390.

3. Deschler B, Lubbert M. Acute myeloid leukemia: epidemiology and etiology. Cancer 2006; 107: 2099-2107.

4. de Lima MC, da Silva DB, Freund AP, Dacoregio JS, Costa Tel J, Costa I, et al. Acute Myeloid Leukemia: analysis of epidemiological profile and survival rate. J Pediatr (Rio J) 2016; 92: 283-289.

5. Puumala SE, Ross JA, Aplenc R, Spector LG. Epidemiology of childhood acute myeloid leukemia. Pediatr Blood Cancer 2013; 60: 728-733.

6. Linabery AM, Ross JA. Trends in childhood cancer incidence in the U.S. (19922004). Cancer 2008; 112: 416-432.

7. Gamis AS, Alonzo TA, Perentesis
JP, Meshinchi S. Children's Oncology Group's 2013 blueprint for research: acute myeloid leukemia. Pediatr Blood Cancer 2013; 60: 964-971.

8. Bayona-Camelo R. Informe final cáncer en menores de 18 años, Colombia 2014. Bogotá D.C., Colombia: Instituto Nacional de Salud. 2014. Disponible: http://www. ins.gov.co/lineas-de-accion/SubdireccionVigilancia/Informe\%20de\%20Evento\%20 Epidemiolgico/Cancer\%20en\%20menores $\% 20$ de $\% 2018 \% 20$ a $\%$ C3\%B1 os $\% 20$ 2014.pdf. Consultado: ago 2015.

9. Vera AM, Pardo C, Duarte MC, Suárez A. Análisis de la mortalidad por leucemia aguda pediátrica en el Instituto Nacional de Cancerología. Biomédica 2012; 32: 355-364.

10. República de Colombia, Ministerio de Salud y Protección Social, Instituto Nacional de Salud. Protocolo de Vigilancia en Salud Pública: Leucemias. Bogotá D.C., Colombia. 2014. Disponible: http:// www.ipsunipamplona.com/es/images/ sampledata/sivigila_2015/protocolos_ epidemiologicos/PRO\%20Leucemias.pdf. Consultado: ago 2015.

11. Piñeros M, Pardo C, Otero J, Suarez A, Vizcaíno M, Garcia S, et al. Protocolo de vigilancia centinela en salud pública de las leucemias agudas pediátricas. Bogotá D.C., Colombia: República de Colombia, Ministerio de Salud y Protección Social, Instituto Nacional de Salud, Instituto $\mathrm{Na-}$ cional de Cancerología. 2008. Disponible: http://www.saludcapital.gov.co/sitios/VigilanciaSaludPublica/Todo\%20Cronicas/ 
Leucemias\%20Agudas\%201.pdf. Consultado: ago 2015.

12. Harris N, Campo E, Jaffe ES, Pileri S, Stein $\mathrm{H}$, Swerdlow $\mathrm{SH}$, et al. Introduction to the WHO classification of tumours of haematopoietic and lymphoid tissues. En: Swerdlow SH, Campo E, Harris NL, Jaffe ES, Pileri SA, Stein $H$, et al., eds. WHO Classification of Tumours of Haematopoietic and Lymphoid Tissues. Lyon, Francia: Who Press; 2008: 14-16.

13. Arber DA, Orazi A, Hasserjian R, Thiele J, Borowitz MJ, Le Beau MM, et al. The 2016 revision to the World Health Organization classification of myeloid neoplasms and acute leukemia. Blood 2016; 127: 2391-2405.

14. Vardiman JW, Brunning AD, Arter DA, Beau MML, Porwit $A$, retten $A$, et al. Introduction and Overview of the Classification of the Myeloid Neoplasms. En: Swerdlow SH, Campo E, Harris NL, Jaffe ES, Pileri SA, Stein $H$, et al., eds. WHO Classification of Tumours of Haematopoietic and Lymphoid Tissues. Lyon, Francia: Who Press; 2008: 17-30.

15. PDQ Pediatric Treatment Editorial Board. Childhood Acute Myeloid Leukemia/Other Myeloid Malignancies Treatment $(P D Q(R))$ : Health Professional Version. PDQ Cancer Information Summaries. Bethesda (MD); 2002.

16. Lanzkowsky P. Leukemias. En: Lanzkowsky P, ed. Manual of Pediatric Hematology and Oncology (ed 4a). Massachusetts, Estados Unidos: Elsevier Academic Press; 2005: 415-452.

17. García-Bernal M, Badell-Serra I. Leucemia en la infancia, signos de alerta. An Pediatr Contin 2012; 10: 1-7.

18. Instituto de Evaluación Tecnológica en Salud (IETS), Centro Nacional de Investigación en Evidencia y Tecnologías en Salud (CINETS). Guía de Práctica Clínica para la detección oportuna, diagnóstico y seguimiento de leucemia linfoide aguda y leucemia mieloide aguda en niños, niñas y adolescentes. Guía No. 9. Bogotá D.C., Colombia: República de Colombia, Ministerio de Salud y Protec- ción Social, Colciencias. 2013. Disponible: https://www.minsalud.gov.co/sites/rid/ Lists/BibliotecaDigital/RIDE/INEC/IETS/ GPC_Comple_Leucemia.pdf. Consultado: ago 2015.

19. Campuzano-Maya G. Interpretación del hemograma automatizado: claves para una mejor utilización de la prueba. Medicina \& Laboratorio 2013; 19: 11-68.

20. Floyd CN, Goodman T, Becker S, Chen N, Mustafa A, Schofield E, et al. Increased platelet expression of glycoprotein IIIa following aspirin treatment in aspirin-resistant but not aspirin-sensitive subjects. Br J Clin Pharmacol 2014; 78: 320-328.

21. Rollig C, Ehninger G. How I treat hyperleukocytosis in acute myeloid leukemia. Blood 2015; 125: 3246-3252.

22. Barnes PW, McFadden SL, Machin SJ, Simson E. The international consensus group for hematology review: suggested criteria for action following automated CBC and WBC differential analysis. Lab Hematol 2005; 11: 83-90.

23. International Society for Laboratory Hematology. Consensus Guidelines: Suggested Criteria for Action Following Automated CBC and WBC Differential Analysis. 2015. Disponible: http://www.islh. org/web/consensus_rules.php. Consultado: abr 2016.

24. Creutzig $U$, van den Heuvel-Eibrink MM, Gibson B, Dworzak MN, Adachi S, de Bont $E$, et al. Diagnosis and management of acute myeloid leukemia in children and adolescents: recommendations from an international expert panel. Blood 2012; 120: 3187-3205.

25. Burger B, Zimmermann M, Mann G, Kuhl J, Loning L, Riehm $H$, et al. Diagnostic cerebrospinal fluid examination in children with acute lymphoblastic leukemia: significance of low leukocyte counts with blasts or traumatic lumbar puncture. J Clin Oncol 2003; 21: 184-188.

26. Arber DA, Brunning RD, Beau MML, Falini B, Vardiman JW, Porwit A, et al. Acute myeloid leukaemia with recurrent 
genetic abnormalities. En: Swerdlow $\mathrm{SH}$, Campo E, Harris NL, Jaffe ES, Pileri SA, Stein $\mathrm{H}$, et al., eds. WHO Classification of Tumours of Haematopoietic and Lymphoid Tissues. Lyon, Francia: Who Press; 2008: 110-123.

27. Creutzig U, Harbott J, Sperling C, Ritter J, Zimmermann M, Loffler $H$, et al. Clinical significance of surface antigen expression in children with acute myeloid leukemia: results of study AML-BFM-87. Blood 1995; 86: 3097-3108.

28. Balgobind BV, Zwaan CM, Pieters R, Van den Heuvel-Eibrink MM. The heterogeneity of pediatric MLL-rearranged acute myeloid leukemia. Leukemia 2011; 25: $1239-1248$.

29. Balgobind BV, Raimondi SC, Harbott J, Zimmermann M, Alonzo TA, Auvrignon $\mathbf{A}$, et al. Novel prognostic subgroups in childhood 11q23/MLL-rearranged acute myeloid leukemia: results of an international retrospective study. Blood 2009; 114: 2489-2496.

30. Arber DA, Heerema-McKenney A. Acute Myeloid Leukemia. En: Jaffe ES, Harris NL, Vardiman JW, Campo E, Arber DA, eds. Hematopathology. Filadelfia, Estados Unidos: Saunders/Elsevier; 2011: 672697.

31. Ostronoff $F$, Othus $M$, Gerbing RB, Loken MR, Raimondi SC, Hirsch BA, et al. NUP98/NSD1 and FLT3/ITD coexpression is more prevalent in younger AML patients and leads to induction failure: a COG and SWOG report. Blood 2014; 124: 2400-2407.

32. Hollink IH, van den Heuvel-Eibrink MM, Arentsen-Peters ST, Pratcorona M, Abbas S, Kuipers JE, et al. NUP98/ NSD1 characterizes a novel poor prognostic group in acute myeloid leukemia with a distinct HOX gene expression pattern. Blood 2011; 118: 3645-3656.

33. Stasevich I, Utskevich R, Kustanovich A, Litvinko N, Savitskaya T, Chernyavskaya S, et al. Translocation $(10 ; 11)$ (p12;q23) in childhood acute myeloid leukemia: incidence and complex mechanism. Cancer Genet Cytogenet 2006;
169: 114-120.

34. Lillington DM, Young BD, Berger $\mathbf{R}_{\boldsymbol{r}}$ Martineau M, Moorman AV, SeckerWalker LM. The $t(10 ; 11)(p 12 ; q 23)$ translocation in acute leukaemia: a cytogenetic and clinical study of 20 patients. European 11q23 Workshop participants. Leukemia 1998; 12: 801-804.

35. de Rooij JD, Hollink IH, Arentsen-Peters ST, van Galen JF, Berna Beverloo H, Baruchel A, et al. NUP98/JARID1A is a novel recurrent abnormality in pediatric acute megakaryoblastic leukemia with a distinct HOX gene expression pattern. Leukemia 2013; 27: 2280-2288.

36. Panagopoulos I, Isaksson M, Billstrom R, Strombeck B, Mitelman F, Johansson B. Fusion of the NUP98 gene and the homeobox gene HOXC13 in acute myeloid leukemia with $\mathrm{t}(11 ; 12)$ (p15;q13). Genes Chromosomes Cancer 2003; 36: 107-112.

37. Tarlock K, Meshinchi S. Pediatric acute myeloid leukemia: biology and therapeutic implications of genomic variants. Pediatr Clin North Am 2015; 62: 75-93.

38. Gruber TA, Larson Gedman A, Zhang J, Koss CS, Marada S, Ta HQ, et al. An Inv(16)(p13.3q24.3)-encoded CBFA2T3GLIS2 fusion protein defines an aggressive subtype of pediatric acute megakaryoblastic leukemia. Cancer Cell 2012; 22: 683-697.

39. Masetti R, Pigazzi M, Togni M, Astolfi A, Indio V, Manara E, et al. CBFA2T3GLIS2 fusion transcript is a novel common feature in pediatric, cytogenetically normal $A M L$, not restricted to $F A B M 7$ subtype. Blood 2013; 121: 3469-3472.

40. SandahI JD, Coenen EA, Forestier E, Harbott J, Johansson B, Kerndrup G, et al. $t(6 ; 9)(p 22 ; q 34) / D E K-N U P 214-r e-$ arranged pediatric myeloid leukemia: an international study of 62 patients. Haematologica 2014 ; 99 : 865-872.

41. Ma Z, Morris SW, Valentine V, Li M, Herbrick JA, Cui $X$, et al. Fusion of two novel genes, RBM15 and MKL1, in the $t(1 ; 22)(p 13 ; q 13)$ of acute megakaryo- 
blastic leukemia. Nat Genet 2001; 28: 220-221.

42. Coombs CC, Tavakkoli M, Tallman MS. Acute promyelocytic leukemia: where did we start, where are we now, and the future. Blood Cancer J 2015; 5: e304.

43. de The $\mathbf{H}$, Chomienne $\mathbf{C}$, Lanotte $\mathbf{M}$, Degos L, Dejean A. The $t(15 ; 17)$ translocation of acute promyelocytic leukaemia fuses the retinoic acid receptor alpha gene to a novel transcribed locus. Nature 1990; 347: 558-561.

44. Longo L, Pandolfi PP, Biondi A, Rambaldi A, Mencarelli A, Lo Coco F, et al. Rearrangements and aberrant expression of the retinoic acid receptor alpha gene in acute promyelocytic leukemias. J Exp Med 1990; 172: 1571-1575.

45. Wang ZY, Chen Z. Acute promyelocytic leukemia: from highly fatal to highly curable. Blood 2008; 111: 2505-2515.

46. Taga T, Tomizawa D, Takahashi H, Adachi S. Acute myeloid leukemia in children: Current status and future directions. Pediatr Int 2016; 58: 71-80.

47. Zhang L, Samad A, Pombo-de-Oliveira MS, Scelo G, Smith MT, Feusner J, et al. Global characteristics of childhood acute promyelocytic leukemia. Blood Rev 2015; 29: 101-125.

48. Forestier E, Heim S, Blennow E, Borgstrom G, Holmgren G, Heinonen $\mathbf{K}$, et al. Cytogenetic abnormalities in childhood acute myeloid leukaemia: a Nordic series comprising all children enrolled in the NOPHO-93-AML trial between 1993 and 2001. $\mathrm{Br} \mathrm{J} \mathrm{Haematol} \mathrm{2003;}$ 121: $566-577$.

49. Byrd JC, Mrozek K, Dodge RK, Carroll AJ, Edwards CG, Arthur DC, et al. Pretreatment cytogenetic abnormalities are predictive of induction success, cumulative incidence of relapse, and overall survival in adult patients with de novo acute myeloid leukemia: results from Cancer and Leukemia Group B (CALGB 8461). Blood 2002; 100: 4325-4336.

50. Ayton PM, Cleary ML. Molecular mechanisms of leukemogenesis mediated by
MLL fusion proteins. Oncogene 2001; 20: 5695-5707.

51. Jones LK, Neat MJ, van Delft FW, Mitchell MP, Adamaki M, Stoneham SJ, et al. Cryptic rearrangement involving MLL and AF10 occurring in utero. Leukemia 2003; 17: 1667-1669.

52. Sambani C, La Starza R, Roumier C, Crescenzi B, Stavropoulou C, Katsarou 0 , et al. Partial duplication of the MLL oncogene in patients with aggressive acute myeloid leukemia. Haematologica 2004; 89: 403-407.

53. Raimondi SC, Chang MN, Ravindranath Y, Behm FG, Gresik MV, Steuber CP, et al. Chromosomal abnormalities in 478 children with acute myeloid leukemia: clinical characteristics and treatment outcome in a cooperative pediatric oncology group study-POG 8821. Blood 1999; 94: 3707-3716.

54. von Bergh A, Emanuel B, van Zelderen-Bhola $S$, Smetsers $T$, van Soest $\mathbf{R}$, Stul M, et al. A DNA probe combination for improved detection of MLL/11q23 breakpoints by double-color interphaseFISH in acute leukemias. Genes Chromosomes Cancer 2000; 28: 14-22.

55. Dyson MJ, Talley PJ, Reilly JT, Stevenson D, Parsons E, Tighe J. Detection of cryptic MLL insertions using a commercial dual-color fluorescence in situ hybridization probe. Cancer Genet Cytogenet 2003; 147: 81-83.

56. Wuchter C, Harbott J, Schoch C, Schnittger S, Borkhardt A, Karawajew L, et al. Detection of acute leukemia cells with mixed lineage leukemia (MLL) gene rearrangements by flow cytometry using monoclonal antibody 7.1. Leukemia 2000; 14: $1232-1238$.

57. Lagunas-Rangel FA. Leucemia mieloide aguda. Una perspectiva de los mecanismos moleculares del cáncer. GAMO 2016; 15: $150-157$.

58. Patel JP, Gönen M, Figueroa ME, Fernandez $H$, Sun $Z$, Racevskis J, et al. Prognostic Relevance of Integrated Genetic Profiling in Acute Myeloid Leukemia. N 
Engl J Med 2012; 366: 1079-1089.

59. Verhaak RG, Goudswaard CS, van Putten W, Bijl MA, Sanders MA, Hugens $\mathbf{W}$, et al. Mutations in nucleophosmin (NPM1) in acute myeloid leukemia (AML): association with other gene abnormalities and previously established gene expression signatures and their favorable prognostic significance. Blood 2005; 106: 3747-3754.

60. Falini B, Bolli N, Liso A, Martelli MP, Mannucci R, Pileri S, et al. Altered nucleophosmin transport in acute myeloid leukaemia with mutated NPM1: molecular basis and clinical implications. Leukemia 2009; 23: 1731-1743.

61. Leroy $\mathbf{H}$, Roumier $\mathbf{C}$, Huyghe $\mathbf{P}$, Biggio $\mathbf{V}$, Fenaux $\mathbf{P}$, Preudhomme C. CEBPA point mutations in hematological malignancies. Leukemia 2005; 19: 329-334.

62. Pabst T, Mueller BU. Complexity of CEBPA dysregulation in human acute myeIoid leukemia. Clin Cancer Res 2009; 15: 5303-5307.

63. Schnittger S, Dicker F, Kern W, Wendland N, Sundermann J, Alpermann T, et al. RUNX1 mutations are frequent in de novo AML with noncomplex karyotype and confer an unfavorable prognosis. Blood 2011; 117: 2348-2357.

64. Mendler JH, Maharry K, Radmacher MD, Mrozek K, Becker H, Metzeler KH, et al. RUNX1 mutations are associated with poor outcome in younger and older patients with cytogenetically normal acute myeloid leukemia and with distinct gene and MicroRNA expression signatures. J Clin Oncol 2012; 30: 3109-3118.

65. Gaidzik VI, Bullinger L, Schlenk RF, Zimmermann AS, Rock J, Paschka P, et al. RUNX1 mutations in acute myeloid leukemia: results from a comprehensive genetic and clinical analysis from the AML study group. J Clin Oncol 2011; 29: 13641372.

66. Conway O'Brien E, Prideaux S, Chevassut $\mathbf{T}$. The epigenetic landscape of acute myeloid leukemia. Adv Hematol 2014; 2014: 103175.
67. Fong CY, Morison J, Dawson MA. Epigenetics in the hematologic malignancies. Haematologica 2014; 99: 1772-1783.

68. Virappane P, Gale R, Hills R, Kakkas I, Summers K, Stevens J, et al. Mutation of the Wilms' tumor 1 gene is a poor prognostic factor associated with chemotherapy resistance in normal karyotype acute myeloid leukemia: the United Kingdom Medical Research Council Adult Leukaemia Working Party. J Clin Oncol 2008; 26: 5429-5435.

69. Renneville A, Boissel N, Zurawski V, Llopis L, Biggio V, Nibourel 0 , et al. Wilms tumor 1 gene mutations are associated with a higher risk of recurrence in young adults with acute myeloid leukemia: a study from the Acute Leukemia French Association. Cancer 2009; 115: 3719-3727.

70. Summers K, Stevens J, Kakkas I, Smith M, Smith LL, Macdougall F, et al. Wilms' tumour 1 mutations are associated with FLT3-ITD and failure of standard induction chemotherapy in patients with normal karyotype AML. Leukemia 2007; 21: 550-551; author reply 552.

71. Gaidzik VI, Schlenk RF, Moschny S, Becker A, Bullinger L, Corbacioglu A, et al. Prognostic impact of WT1 mutations in cytogenetically normal acute myeloid leukemia: a study of the German-Austrian AML Study Group. Blood 2009; 113: 4505-4511.

72. Cuervo-Sierra J, Jaime-Pérez JC, Gómez-Almaguer D. Mutaciones del módulo FLT3 en leucemia aguda mieloblástica. Rev Hematol Mex 2012; 13: 177-184.

73. Krstovski N, Tosic N, Janic D, Dokmanovic $L$, Kuzmanovic M, Spasovski $V$, et al. Incidence of FLT3 and nucleophosmin gene mutations in childhood acute myeloid leukemia: Serbian experience and the review of the literature. Med Oncol 2010; 27: 640-645.

74. Meshinchi S, Woods WG, Stirewalt DL, Sweetser DA, Buckley JD, Tjoa TK, et al. Prevalence and prognostic significance of Flt3 internal tandem duplication in pediatric acute myeloid leukemia. 
Blood 2001; 97: 89-94.

75. Ravandi F, Kantarjian H, Faderl S, Garcia-Manero G, O'Brien S, Koller C, et al. Outcome of patients with FLT3mutated acute myeloid leukemia in first relapse. Leuk Res 2010; 34: 752-756.

76. Small D. FLT3 mutations: biology and treatment. Hematology Am Soc Hematol Educ Program 2006: 178-184.

77. Manara E, Basso G, Zampini M, Buldini B, Tregnago $C$, Rondelli $R$, et al. Characterization of children with FLT3-ITD acute myeloid leukemia: a report from the AIEOP AML-2002 study group. Leukemia 2016.

78. Gao W, Estey E. Moving toward targeted therapies in acute myeloid leukemia. Clin Adv Hematol Oncol 2015; 13: 748-754.

79. Arber DA, Brunning RD, Orazi A, Porwit A, Peterson L, Thiele J, et al. Acute myeloid leukaemia, not otherwise specified. En: Swerdlow SH, Campo E, Harris NL, Jaffe ES, Pileri SA, Stein $H$, et al., eds. WHO Classification of Tumours of Haematopoietic and Lymphoid Tissues. Lyon, Francia: Who Press; 2008: 130139.

80. Caldwell JT, Ge Y, Taub JW. Prognosis and management of acute myeloid leukemia in patients with Down syndrome. Expert Rev Hematol 2014; 7: 831-840.

81. Gamis AS, Alonzo TA, Gerbing RB, Hilden JM, Sorrell AD, Sharma M, et al. Natural history of transient myeloproliferative disorder clinically diagnosed in Down syndrome neonates: a report from the Children's Oncology Group Study A2971. Blood 2011; 118: 6752-6759; quiz 6996.

82. Zipursky A. Transient leukaemia--a benign form of leukaemia in newborn infants with trisomy 21. Br J Haematol 2003; 120: 930-938.

83. Groet J, McElwaine S, Spinelli M, Rinaldi A, Burtscher $I$, Mulligan $C$, et al. Acquired mutations in GATA1 in neonates with Down's syndrome with transient myeloid disorder. Lancet 2003; 361: 1617-1620.
84. Rainis L, Bercovich D, Strehl S, Teigler-Schlegel A, Stark B, Trka J, et al. Mutations in exon 2 of GATA1 are early events in megakaryocytic malignancies associated with trisomy 21. Blood 2003; 102: 981-986.

85. Bruwier A, Chantrain CF. Hematological disorders and leukemia in children with Down syndrome. Eur J Pediatr 2012; 171: 1301-1307.

86. Fernandez-Plaza S, Sevilla J, Contra T, Martin N, Madero L. [Acute leukemia in patients with Down syndrome]. An Pediatr (Barc) 2004; 61: 515-519.

87. Langebrake $\mathbf{C}$, Creutzig $\mathbf{U}$, Reinhardt D. Immunophenotype of Down syndrome acute myeloid leukemia and transient myeloproliferative disease differs significantly from other diseases with morphologically identical or similar blasts. Klin Padiatr 2005; 217: 126-134.

88. Seewald L, Taub JW, Maloney KW, McCabe ER. Acute leukemias in children with Down syndrome. Mol Genet Metab 2012; 107: 25-30.

89. Yoshida K, Toki T, Okuno Y, Kanezaki $\mathbf{R}$, Shiraishi $Y$, Sato-Otsubo A, et al. The landscape of somatic mutations in Down syndrome-related myeloid disorders. Nat Genet 2013; 45: 1293-1299.

90. Mansini AP, Rubio PL, Rossi JG, Gallego MS, Medina A, Zubizarreta PA, et al. Mutation characterization in the GATA-1 gene in patients with Down's Syndrome diagnosed with transient abnormal myelopoiesis or acute megakaryoblastic leukemia. Arch Argent Pediatr 2013; 111: 532-536.

91. Creutzig U, Reinhardt D, Diekamp S, Dworzak M, Stary J, Zimmermann $\mathbf{M}$. AML patients with Down syndrome have a high cure rate with AML-BFM therapy with reduced dose intensity. Leukemia 2005; 19: $1355-1360$.

92. Chen SJ, Shen Y, Chen Z. A panoramic view of acute myeloid leukemia. Nat Genet $2013 ; 45$ : 586-587. 


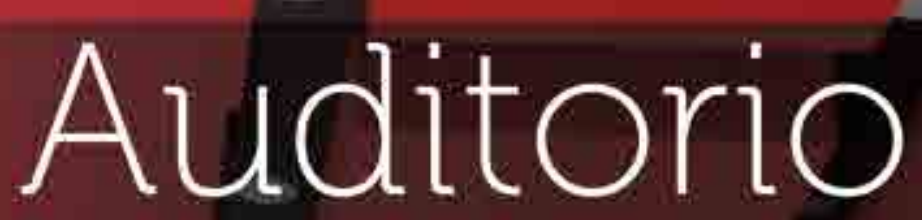

\section{Un espacio a su servicio}

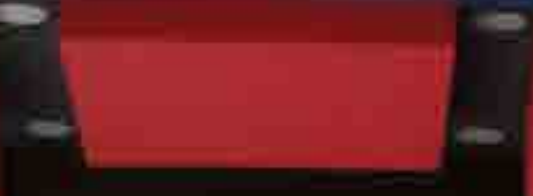

Auditorio tipo teatro

Ideal para convenciones; reuniones empresariales, conferencias, seminarios,

cursos, foros y muestras comerciales

Capacidad para 150 personas

Sistema de sonido acûstico profesional

Parqueadero robotizado para 95 vehiculos

Ubicado en el moderno edificio del Laboratorio Clínico Hematológico
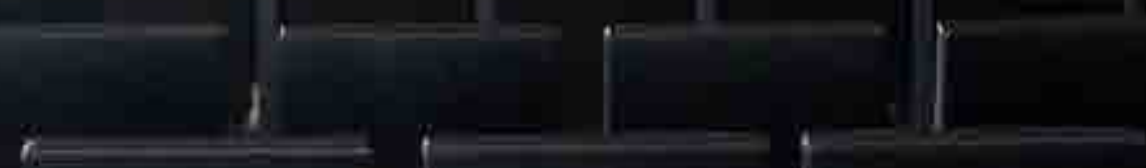

Carrera 43 C \# 5 - 33. Patio Bonito, El Poblado Medellin-Antioquia

Mayor información: 4444900

EDIMECO

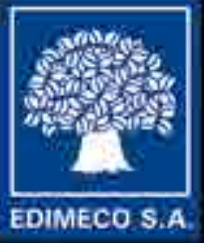

